\title{
The coregulator exchange in transcriptional functions of nuclear receptors
}

\author{
Christopher K. Glass ${ }^{1}$ and Michael G. Rosenfeld ${ }^{2,3}$ \\ ${ }^{1}$ Department of Cellular and Molecular Medicine, Department of Medicine, University of California, San Diego, La Jolla, \\ California 92093-0651 USA; ${ }^{2}$ Howard Hughes Medical Institute, Department of Medicine, University of California, San \\ Diego, La Jolla, California 92095-0648 USA
}

Nuclear receptors (NR) comprise a family of transcription factors that regulate gene expression in a liganddependent manner. Members of the NR superfamily include receptors for steroid hormones, such as estrogens (ER) and glucocorticoids (GR), receptors for nonsteroidal ligands, such as thyroid hormones (TR) and retinoic acid (RAR), as well as receptors that bind diverse products of lipid metabolism, such as fatty acids and prostaglandins (for review, see Beato et al. 1995; Chambon 1995; Mangelsdorf and Evans 1995). The NR superfamily also includes a large number of so-called orphan receptors for which regulatory ligands have not been identified (Mangelsdorf and Evans 1995). Although many orphan receptors are likely to be regulated by small-molecular-weight ligands, other mechanisms of regulation, such as phosphorylation (Hammer et al. 1999; Tremblay et al. 1999) have also proven to be of importance. Remarkably, the sequence of the Caenorhabditis elegans genome has revealed the presence of $>200$ members of the NR family, suggesting a critical role of these proteins in environmental adaptation (Sluder et al. 1999). Although mammalian genomes are unlikely to contain such a large complement of these factors, $>24$ distinct classes of NR have been identified in humans, and these factors exert diverse roles in the regulation of growth, development, and homeostasis. Based on their importance in biology and medicine, as well as the relatively simple mechanism of regulation, NR represent one of the most intensively studied and best-understood classes of transcription factors at the molecular level.

Members of the NR family regulate transcription by several mechanisms (Fig. 1). Nuclear receptors can activate or repress target genes by binding directly to DNA response elements as homo- or heterodimers or by binding to other classes of DNA-bound transcription factors. A subset of NRs, including TR and RAR, can actively repress target genes in the presence or absence of ligand

${ }^{3}$ Corresponding author.

E-MAIL mrosenfeld@ucsd.edu; FAX (858) 534-8180. binding, and many NR have been demonstrated to inhibit transcription in a ligand-dependent manner by antagonizing the transcriptional activities of other classes of transcription factors. These activities have been linked to interactions with general classes of molecules that appear to serve coactivator or corepressor function. In this review, we will discuss recent progress concerning the molecular mechanisms by which NR cofactor interactions serve to activate or repress transcription.

\section{Coactivators in transcriptional regulation by NRs}

The ability to switch a nuclear receptor from an inactive to an active state by simple addition of a small molecule in vitro has dramatically facilitated biochemical approaches to the elucidation of their mechanisms of action, providing instructive insights with respect to mechanisms of transcriptional activation by other classes of signal-dependent transcription factors. The NR ligand-binding domain (LBD) is connected to the DNA-binding domain by a short flexible linker and mediates ligand-dependent transactivation functions. A short conserved helical sequence within the carboxyl terminus of the LBD, referred to as activation function 2 (AF-2), is required for ligand-dependent activation (Danielian et al. 1992; Durand et al. 1994). Biochemical and expression cloning approaches have been used to identify a large number of factors that interact with NRs in either a ligand-independent or ligand-dependent manner. Many of these factors have been demonstrated to be capable of potentiating NR activity in transient cotransfection assays, suggesting their potential to serve as NR coregulators. Many of these proteins also appear to function as components of large, multiprotein complexes. As the number of potential coregulators clearly exceeds the capacity for direct interaction by a single receptor, the most parsimonious hypothesis is that transcriptional activation by NRs involves multiple factors that act in both a sequential and combinatorial manner to reorganize chromatin templates (Pollard and Peterson 1998), 


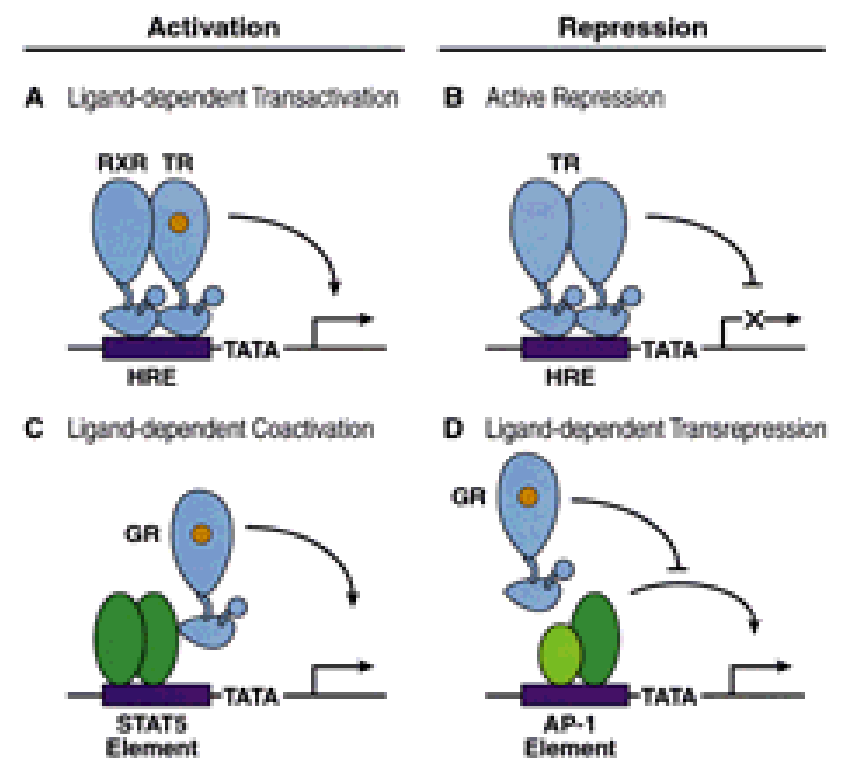

Figure 1. Transcriptional activities of NRs. Members of the NR family can both activate and inhibit gene expression. (A) The prototypic activity of NRs is ligand-dependent activation of transcription upon binding to specific hormone-response elements (HREs) in target genes. (C) NRs have also been documented to contribute to gene activation by acting as coactivators for other transcription factors, as demonstrated in the case of the glucocorticoid receptor for certain STAT-5-responsive genes. (E) A number of orphan NRs, such as CAR $\beta$ and HNF4, are capable of constitutively activating transcription. Several mechanisms of transcriptional inhibition have also been established. (B) A subset of NRs that heterodimerize with the retinoid $\mathrm{X}$ receptor, including the thyroid hormone receptor (TR) and retinoic acid receptor (RAR), are capable of actively repressing target genes upon binding to HREs in the absence of ligand. $(D)$. In addition, several NRs, exemplified by the glucocorticoid receptor are capable of inhibiting the activities of other classes of transcription factors, such as AP-1, in a ligand-dependent manner. This effect does not require DNA binding by the NR and is referred to as transrepression.

and to modify and recruit basal factors and RNA polymerase II.

A combination of genetic, biochemical, and functional data suggests that several factors, including the $\mathrm{Brg}$ (SWI/SNF) complex, CBP/p300, p160 factors, P/CAF, and the TRIP/DRIP/ARC complexes, discussed below, are likely to be critical regulators for at least subsets of NR-regulated genes (Fig. 2). However, by the simple criteria of ligand-dependent binding and the ability to synergize on cotransfection assays, numerous additional proteins have been suggested to exert coactivator roles. These include HMG factors (Verrier et al. 1997; Boonyaratanakornkit et al. 1998; Romine et al. 1998), MEF2 (Lee et al. 1997), cell cycle regulators such as cyclin D (Zwijsen et al. 1997), the ADA coactivators in a yeast context (vom Baur et al. 1998), ARA5Y (Kang et al. 1999), the ring finger SNURF (Moilanen et al. 1998), the vitamin D coactivator NCOA-62 (Baudino et al. 1998), as well as PC2 and PC4 (Fondell et al. 1999). The potential actions of E6-AP (Huibregtse et al. 1995; Imhof and McDonnell 1996; Nawaz et al. 1999) provides intriguing questions regarding proteolytic events. TRIP-1/Sug1 (Lee et al. 1995a,b), identified as a suppressor of Gal4dependent activation, has been copurified (Rubin et al. $1996)$ as a component of the 2-MD yeast 26S protoesomal complex, and correlated with reduced ubiquitindependent proteolysis in Sug-1 mutants. The potential relationship of proteosomal activity to NR function is tantalizing but unclear; it could ultimately relate to "switching" of receptor-associated complexes.

\section{Swi/Snf/BRG complexes: ATP-dependent chromatin remodeling complexes}

As chromatinized transcription units are repressed as compared to naked DNA, a critical aspect of gene activation involves nucleosomal remodeling (for review, see Wu 1997; Wade and Wolffe 1999). Two general classes of chromatin remodeling factors have been identified that appear to play critical roles in transcriptional activation by NRs; ATP-dependent nucleosome remodeling complexes, and factors that contain histone acetyltransferase activity (for review, see Kingston and Narlikar 1999). Recent work has led to the discovery of several activities that use ATP hydrolysis in the remodeling of chromatin templates and appear to be involved in NR function. At least two related remodeling complexes are present in yeast; RSC (remodeling the structure of chromatin) (Cairns et al. 1996; Pollard and Peterson 1998) and the SWI/SNF complex. The SWI2/SNF2 gene identified encodes a protein that is homologous to DNA-stimulated ATPases/DNA helices (Laurent et al. 1993; Cairns et al. 1996). The yeast SWI/SNF complex (for review, see Peterson 1996; Workman and Kingston 1998) facilitates the binding of sequence-specific transcription factors to nucleosomal DNA and has the ability to cause local changes in chromatin structure in an ATP-dependent manner (Owen-Hughes et al. 1996). Homologs of SWI2/ SNF2 are present in flies (Brahma) and mammals (BRG1, $\mathrm{hBrm})$, in each case functioning as components of large multiprotein complexes (Tamkun et al. 1992; Khavari et al. 1993; Muchardt and Yaniv 1993; Dingwall et al. 1995; Tsukiyama and Wu 1995). Remodeling complexes similar to the SWI/SNF complex have been characterized in Drosophila, including NURF (nucleosome remodeling factor) (Tamkun et al. 1992), ACF (ATTP-utilizing chromatin assembly and remodeling factor) (Ito et al. 1997) and CHRAC (chromatin accessibility complex (VargaWeisz et al. 1997). All of these complexes contain ISWI (imitation SWI), a member of the SWI2/SNF2 family, suggesting that this protein may serve as the energytransducing component of chromatin-remodeling machines. These findings indicate that there are a number of chromatin remodeling activities that can generate local modifications in nucleosomes, suggesting a level of combinatorial control even at this step in the activation process.

Although yeast do not contain NRs, a role for SWI/ 


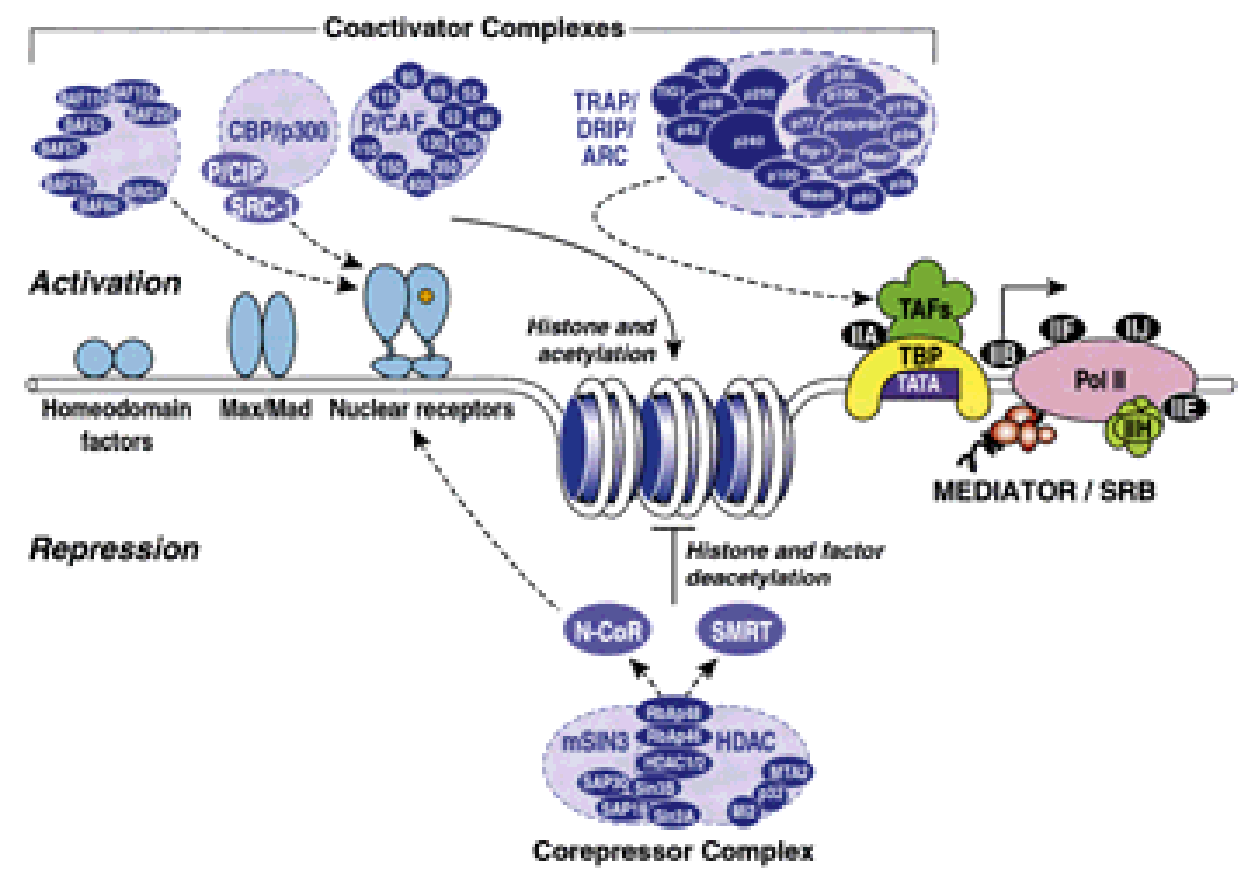

Figure 2. Coactivator and corepressor complexes in NR transcription. Coactivator complexes include SWI/SNF, CBP/SRC-1/p/CAF and TRAP/DRIP/ARC. The SWI/SNF complex possesses ATP-dependent chromatin remodeling activities. The CBP and p/CAF complexes possess histone acetyltransferase activities. These complexes may act in concert to relieve chromatin-mediated repression, with the TRAP/DRIP/ARC complex functioning to recruit core transcription factors. Corepressor complexes include the SIN3/HDAC complex, which has been proposed to be recruited via the NR corepressors NCoR or SMRT. This complex possesses histone deacetylase activity and is thought to reverse actions of histone acetyltransferase-containing complexes.

SNF complexes was initially suggested based on experiments demonstrating that GR activity in yeast required these factors (Yoshinaga et al. 1992). The GR can target the SWI/SNF complex to chromatinized templates containing GR binding sites in yeast, resulting in disruption of local nucleosomal structure (Ostlund Farrants et al. 1997). However, in yeast this action did not appear to require the presence of ligand. Both hBrm and Brg-1 have been shown to interact with the ER in a ligand-dependent fashion using the yeast two-hybrid assay (Ichinose et al. 1997). Transfection of an ATPase and defective allele of either Brgl or hBrm into several mammalian cell lines leads to a significant decrease in the ability of NRs, including RAR, ER, and GR to activate transcription (Muchardt and Yaniv 1993; Chiba et al. 1994). Studies of the ability of the GR to activate transcription from the mouse mammary tumor virus (MMTV) promoter in mammalian cells indicates that interaction with Brg-1-containing complexes was required when the promoter was integrated stably into chromosomal DNA, but not when the promoter was assessed in transiently transfected cells (Fryer and Archer 1998). ISWI-containing complexes are reported to be targeted by the progesterone receptor to the MMTV promoter, resulting in topographical alterations (Di Croce et al. 1999|. These observations are consistent with the possibility that chromatin remodeling at the promoter may represent the first step in the activation of transcription in vivo.

\section{Complexes with histone/protein acetyltransferase activity}

The discovery that the Tetrahymena histone acetyltransferase A was related to the yeast transcriptional regulator GCN5 (Brownell et al. 1996) suggested a direct link between a histone modification that previously had been correlated with transcriptionally active genes and the function of a transcriptional coactivator. The rates of gene transcription roughly correlate with the degree of histone acetylation, with hyperacetylated regions of the genome being more actively transcribed than hypoacetylated regions (for review, see Pazin and Kadonaga 1997). Thus, the specific recruitment of a complex with histone acetyltransferase (HAT) activity to a promoter may play a critical role in overcoming repressive effects of chromatin structure on transcription (Pazin and Kadonaga 1997; Struhl 1998; Wade et al. 1998). This concept was further supported by the subsequent finding that the mammalian GCN5 ortholog P/CAF (Yang et al. 1996), CREB binding protein (CBP) (Bannister and Kouzarides 1996; Ogryzko et al. 1996), the adenovirus E1A binding protein p300 (Ogryzko et al. 1996), and TAF $_{\text {II }} 250$ (Mizzen et al. 1996), each possess intrinsic HAT activity. Conversely, the discovery that a mammalian histone deacetylase (HDAC) was a homolog of the yeast corepressor, RPD3 (Taunton et al. 1996), gave rise to the hypothesis that regulated activation events might involve the exchange of complexes containing histone deacety- 
lase function with those containing HAT activity (Fig. 2).

However, the significance of the acetylation of lysine residues in the short amino-terminal domains of core histones is not fully elucidated. Possibilities considered include altered nucleosomal placement, for which there is no evidence (Logie et al. 1999). Because hyperacetylation may slightly reduce thermal stability, the binding of some transcription factors may be enhanced. The only argument for altered conformation of nucleosomal core particles comes from slight effects on average linkage number of nucleosomes of a supercoiled plasmid (Barnes et al. 1994). Indeed, in examining ligand-dependent transcription by the $\mathrm{T} 3$ receptor in Xenopus, there was no significant evidence of nucleosomal rearrangement (Li et al. 1999). A second role involves abolishing the aminoterminal chromatin-dependent intermolecular folding that might reflect chromosomal condensation (for review, see Fletcher and Hansen 1996). The most important role might be to influence binding of other regulatory factors, such as TUP1 in yeast, with specificity provided by sites on histones that are acetylated (Hecht et al. 1995; Edmondson et al. 1996; Kuo et al. 1996; Pollard and Peterson 1998).

\section{$P / C A F$}

$\mathrm{P} / \mathrm{CAF}$ and GCN5e are homologs of the yeast protein GCN5, which is an essential component of multisubunit coactivator complexes referred to as the ADA or SAGA complexes (Grant et al. 1997, 1998a). The yeast SAGA complex contains at least two groups of gene products; the Ada proteins Gcn5, Ada1, Ada2, Ada3, and Ada5 and the TATA-binging protein (TBP)-related set of Spt proteins, Spt3, Spt7, Spt8 and Spt20. Purification of the SAGA complex has revealed that it also contains a subset of proteins TBP-associated factor) (TAF), including $\operatorname{TAF}_{\text {II }} 90, \operatorname{TAF}_{\text {II }} 68 / 61, \operatorname{TAF}_{\text {II }} 60, \operatorname{TAF}_{\text {II }} 25 / 23$, and TAF $\operatorname{TA}_{\mathrm{II}} 20 /$ 17 (Grant et al. 1998a,b). Tra1, an ATM/PI-3-kinase-related homolog of a human cofactor essential for c-myc and E2F transformation, has recently been identified as an additional component of SAGA (Grant et al. 1998a). The SAGA complex exerts transcriptional activity in vitro only on chromatinized templates and depends on the HAT activity of Gcn5 (Brownell et al. 1996); however the ability of Gen5 to acetylate nucleosomal histones requires additional components of the SAGA complex.

Using an affinity purification approach, a mammalian core $\mathrm{P} / \mathrm{CAF}$ complex was recently isolated that contained members of the ADA family as well as TAFs (Ogryzko et al. 1998). This P/CAF complex thus bears clear resemblance to the SAGA complex in yeast, hinting at a link between the P/CAF complex and the core machinery. Other subunits of the complex enable $\mathrm{P} / \mathrm{CAF}$ to acetylate histones in the context of nucleosomes, which apo-P/CAF alone fails to do, similar to the requirement of yeast Gcn5 for components of the SAGA complex to acetylate nucleosomes (Grant et al. 1997).

Like Gcn5, P/CAF contains a carboxy-terminal region that contains protein-protein interaction motifs. In ad- dition, $\mathrm{P} / \mathrm{CAF}$ contains an amino-terminal extension not conserved in yeast GCN5 that appears to mediate additional protein-protein interactions. Although initially identified as a factor that interacts with the $\mathrm{C} / \mathrm{H} 3$ domains of p300 and CBP (Yang et al. 1996), studies have subsequently demonstrated that $\mathrm{P} / \mathrm{CAF}$ is capable of interacting with other domains, CBP/p300 with other NR coactivators (Chen et al. 1997; Blanco et al. 1998; Korzus et al. 1998), and with the LBD of the RAR, in a ligandindependent fashion (Blanco et al. 1998). P/CAF has thus been suggested to exert roles in mammalian cells in NR activation events.

\section{CBP/p300}

CBP and p300 serve essential coactivator roles for many classes of sequence-specific transcription factors (for review, see Torchia et al. 1997; McKenna et al. 1999), functioning in part by acting as molecular scaffolds, and in part by acetylating diverse substrates. The intrinsic acetyltransferase activity of CBP and p300 was demonstrated initially using histones as substrates. In vitro, CBP and p300 not only acetylate free histones but also histones assembled into nucleosomal complexes, suggesting that nucleosomes can be similarly modified in vivo /Ogryzko et al. 1996).

Evidence for important roles of CBP/p300 in NR function in cells has been provided by the results of genedeletion experiments, nuclear injection of blocking antibodies, and transfection assays /Chen and Okayama 1987; Chakravarti et al. 1996; Hanstein et al. 1996; Kamei et al. 1996; Yao et al. 1996, 1998; Kawasaki et al. 1998). Cell-free transcription assays of ER activity are consistent with a role of p300 in overcoming chromatinmediated repression (Kraus and Kadonaga 1998). When ER activity is assessed on naked DNA templates, high rates of transcription are observed that are relatively ligand-independent. When assessed on chromatinized templates in the presence of defined core transcription factors, both basal and ligand-dependent transcription are markedly repressed. Addition of p300 does not significantly influence basal transcription, but markedly stimulates ligand-dependent activity. Evidence for differences in p300 and CBP function has been suggested by analysis of in vivo gene deletion experiments, genetic diseases, which reveal distinct phenotypes (Miller and Rubinstein 1995; Petrij et al. 1995; Tanaka 1997; Yao et al. 1998; Oike et al. 1999a,b), and by results using specific hammerhead ribozymes (Kawasaki et al. 1998).

CBP and p300 acetylate a range of substrates, including sequence-specific transcription factors. For example, the carboxy terminus of unmodified p53 inhibits its ability to bind to DNA, but is efficiently acetylated by CBP and p300 (Gu et al. 1999). Upon acetylation, this inhibitory effect is relieved, allowing high affinity DNA binding. Additional nonhistone proteins that have been identified as substrates of p300 and CBP include HMG I/Y (Munshi et al. 1998). Intriguingly, it has been proposed that acetylation of HMG I/Y may play a role in termination of transcriptional activation. In the case of some 
interactions, acetylation appears to serve as a negative transcriptional signal such as in the case of TCF (Waltzer and Bienz 1998). In turn, it has been proposed that covalent modifications and association with other factors, such as E1A, modulate CBP HAT activity. In vivo, E1A has been suggested to enhance histone acetylation (AitSi-Ali et al. 1998), whereas in biochemical assays using either specific histones or HMG proteins as substrates (Chakravarti et al. 1999; Hamamori et al. 1999; Perissi et al. 1999a), E1A at high levels can be inhibitory to both $\mathrm{CBP}$ and P/CAF acetyltransferase function. However EIA can inhibit the acetylation of other substrates ( $\mathrm{Li}$ et al. 1999). This inhibition has been alternatively ascribed to interactions with the HAT domain itself (Chakravarti et al. 1999), or rather to be dependent upon specific interactions with the $\mathrm{C} / \mathrm{H} 3$ domain (Perissi et al. 1999). Although the biological significance of these observations is not at all clear, they raise the possibility that the HAT activity of CBP, and potentially other HAT-containing factors, may be regulated.

The ability of CBP to coordinate the assembly of additional protein complexes appears to be an essential aspect of its function as a coactivator. Biochemical studies suggest that CBP serves as a coactivator of CREB in part by recruitment of RNA polymerase II (pol II) complexes (Nakajima et al. 1996). Transcriptional activation by CREB is strongly inhibited by E1A, which binds to CBP and p300 via the C/H3 domain (Arany et al. 1994; Eckner et al. 1994), as well as to amino-terminal and carboxyterminal sites (Kurokawa et al. 1998). The C/H3 region interacts with several proteins, including RNA helicase A, which is a component of RNA pol II complexes (Nakajima et al. 1997). Indeed, immunoprecipitation experiments indicate that a fraction of RNA pol II in the cell can be coprecipitated with antibodies specific for CBP. These findings suggest that E1A inhibits the function of CREB by preventing the assembly of CBP-coactivator complexes that contain RNA pol II. In the case of the RAR, interaction of CBP with SRC-1 appeared to be critical for ligand-dependent transcription, with the $\mathrm{C} / \mathrm{H} 3$ domain of CBP not being required. Intriguingly, the interaction of E1A with the carboxyl terminus of CBP prevents the assembly of CBP/SRC-1 coactivator complexes, indicating that there may be factor-specific mechanisms of transcriptional inhibition by this factor (Kurokawa et al. 1998).

\section{p160/SRC}

Proteins of $\sim 160 \mathrm{kDa}$ molecular mass were among the first factors identified that interact with NRs in a highly ligand-dependent, both in solution (Cavailles et al. 1994; Halachmi et al. 1994) or on DNA (Kurokawa et al. 1995). These biochemically identified factors could themselves associate with CBP (Kamei et al. 1996; Yao et al. 1996). Expression cloning and yeast two-hybrid screening approaches led to the identification of three related genes that encode the p160 factors, referred to as SRC-1/NcoA1, p160, TIF2/GRIP-2/NcoA-1 and p/CIP/AIB-1/ACTR/ RAC/TRAM-1 (Onate et al. 1995; Kamei et al. 1996;
Anzick et al. 1997; Chen et al. 1997; Hong et al. 1997; Li et al. 1997a; Takeshita et al. 1997; Torchia et al. 1997). Members of the p160 family of NR coactivators contain a highly conserved amino-terminal basic helix-loop-helix (bHLH) PAS domain that is also present in members of the Per/Arnt/Sim family of transcription factors and mediates protein-protein interactions (see Fig. 5A, below). Several lines of evidence support the idea that p160 factors play important roles as NR coactivators, however the extent of their role is not proven. Consistent with potential redundancy, the knockout of the $S R C$ - 1 gene in mice results in relatively subtle defects in the development of estrogen-dependent tissues, including the uterus and breast, which may be explained by the observed compensatory increases in TIF-2 expression (Xu et al. 1998). No apparent defects in PPAR $\gamma$-function have been documented in SRC-1-deficient mice (Qi et al. 1999).

The carboxyl terminus of SRC-1 (Spencer et al. 1997) and ACTR (Chen et al. 1997) have been reported to possess HAT activity. This activity is much weaker than the HAT activity of $\mathrm{CBP} / \mathrm{p} 300$, and $\mathrm{p} / \mathrm{CAF}$, and the carboxyl terminus of SRC-1 and ACTR do not appear to contain features that correspond to the acetyl CoA binding site of the P/CAF (Clements et al. 1999), or GCN5 HAT domains (Trievel et al. 1999). The crystal structures of GCN5 and P/CAF are conserved in the CBP HAT domain (Martinez-Balbas et al. 1998), suggesting that the ACTR/SRC-1 HAT activities reflect entirely novel structures. Additional factors may be recruited to specific domains of the p160 factor; for example, a novel protein methyltransferase may be recruited to the p160 carboxyl terminus. This coactivator-associated arginine methyltransferase, CARM1, has selective functional effects on transcriptional activation by NRs, and can methylate histone H3 in vitro (Chen et al. 1999a), thus the platform assembly functions of p160 factors includes recruitment of factors with methyltransferase functions.

Studies also suggest that the same coactivator complexes can be utilized differentially by different classes of signal-dependent transcription factors, perhaps altering factor-specific acetyltransferase requirements (Woloshin et al. 1995; Puri et al. 1997; Korzus et al. 1998; Xu et al. 1998), consistent with the idea that HAT activity is not the only functional property of $\mathrm{CBP} / \mathrm{p} 300$ and P/CAF.

\section{TRAP/DRIP/ARC}

In a pioneering study, epitope-tagged TR expressed in a permanent cell line was used to affinity purify TR-associated proteins (TRAPs) (Fondell et al. 1996a). Several proteins were copurified in an apparent stoichiometric ratio, suggesting the presence of a complex (Fig. 3). This putative TRAP complex enhanced in vitro transcriptional activation of TR in a chromatin-free system (Fondell et al. 1996b, 1999). A very similar complex of vitamin D receptor (VDR) interacting proteins (DRIPs) was isolated, using VDR (Rachez et al. 1998). Purified DRIP complex substantially potentiated ligand-dependent transactivation function of VDR on a chromatinized template in vitro (Rachez et al. 1999). In each complex, 
Figure 3. Utilization of multiple coactivator complexes. In the first model, one complex is recruited to carry out acetyltransferase reactions and recruit additional proteins. Upon completion of these functions, this complex leaves the promoter and is replaced by a second complex, that performs a distinct set of steps required for recruitment of core factors and transactivation. Alternatively, an overlap of combinatorial utilization of multiple coactivator complexes may be required for physiologic levels of expression on specific promoters. For example, the CBP/SRC-1/pCAF and TRAP/GRIP/ARC complexes may synergize on a subset of promoters, whereas on another set of promoters the utilization of gene or cell-specific coactivators such as PGC-1 may be required. Finally, activation of the same gene by different coactivator complexes, permitting different responses to specific signaling pathways.

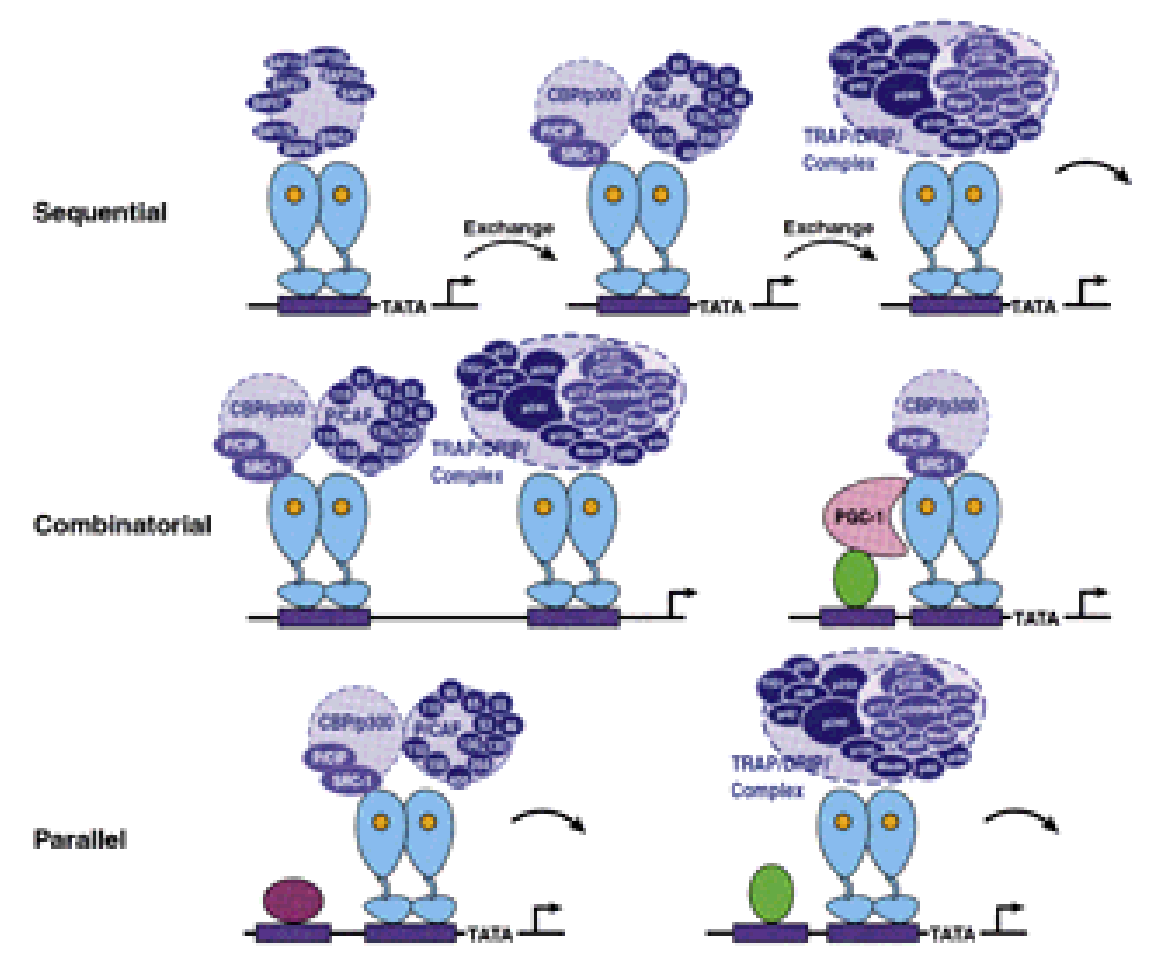

at least nine proteins, ranging from $\sim 70 \mathrm{kD}$ to $\sim 230 \mathrm{kD}$, were noted. Surprisingly, several constituents of the TRAP/DRIP/ARC (activator-recruited cofactor) complex are similar if not identical to protein components of the recently identified CRSP, NAT, and SMCC complexes (Fig. 3) (Hampsey and Reinberg 1999). These complexes, which were isolated independently, have been found to be required for in vitro transcriptional activation from chromatin templates by a number of other transcription factors, including SREBP, NFкB, and VP16 (Sun et al. 1998; Gu et al. 1999; Ito et al. 1999; Naar et al. 1999; Ryu et al. 1999). Thus, TRAP/DRIP/ARC is a large composite coactivator that belongs to a family of related cofactors and is targeted by different classes of activator to mediate transcriptional stimulation.

Although the TRAP/DRIP/ARC complex has stimulating activity on chromatinized templates (Rachez et al. 1999) it does not contain intrinsic HAT activity (Yuan et al. 1998). Of note is that many components of this complex are also present in a mammalian complex corresponding to the yeast mediator (Gu et al. 1999). The striking similarity in a number of components of the mediator complex and the DRIP/TRAP/ARC complex raises interesting issues of the level at which this complex functions. The TRAP/DRIP/ARC complex has subsequently been shown to contain a factor (TRAP 220/ DRIP 205/TRIP2/mPIP1) identical to a PPAR $\gamma$-interacting protein, PBP (Lee et al. 1995a; Zhu et al. 1997; Rachez et al. 1998; Yuan et al. 1998). This factor appears to mediate the interaction of the TRAP/DRIP/ARC complexes with NRs in response to activating ligands (Yuan et al. 1998; Treuter et al. 1999).

\section{Sequential and combinatorial actions of coactivator complexes}

The extraordinary number of factors that appear to be involved in transcriptional activation by NRs represents a formidable challenge to understanding how so many different proteins cooperate in gene activation. For example: are the chromatin remodeling factors recruited to specific promoters? Why are there multiple complexes with HAT activity? Is there a temporal order to the recruitment of CBP/SRC and TRAP/DRIP/ARC complexes to ligand-activated receptors, or do these complexes define parallel pathways for transcriptional activation? These alternative possibilities are schematically indicated in Fig. 3.

Kinetically, transcription may be viewed as a multistep procedure, a derepression process followed by transcriptional initiation. The former refers to relief of the repression imposed by high order chromatin structure; and the latter is assembly of the core RNA polII machinery and the initiation of transcription. Recent studies of mechanisms regulating transcription of the $H O$ gene in yeast may providing insights into temporal aspects of gene activation by NRs. HO regulates mating type switching and is subject to complex combinatorial control. During budding, $\mathrm{HO}$ is transiently expressed in late G1 of the cell cycle of the mother cell but at no stage of the daughter cell (actually a small percentage of cells can express $\mathrm{HO}$ ). Transcription of $\mathrm{HO}$ is regulated by factors binding to URS-1 and URS-2 (cell cycle-dependent regulatory regions) (Fig. 4B). Using the chromatin immuno precipitaion (CHIP) assay in a series of genetic back- 
A
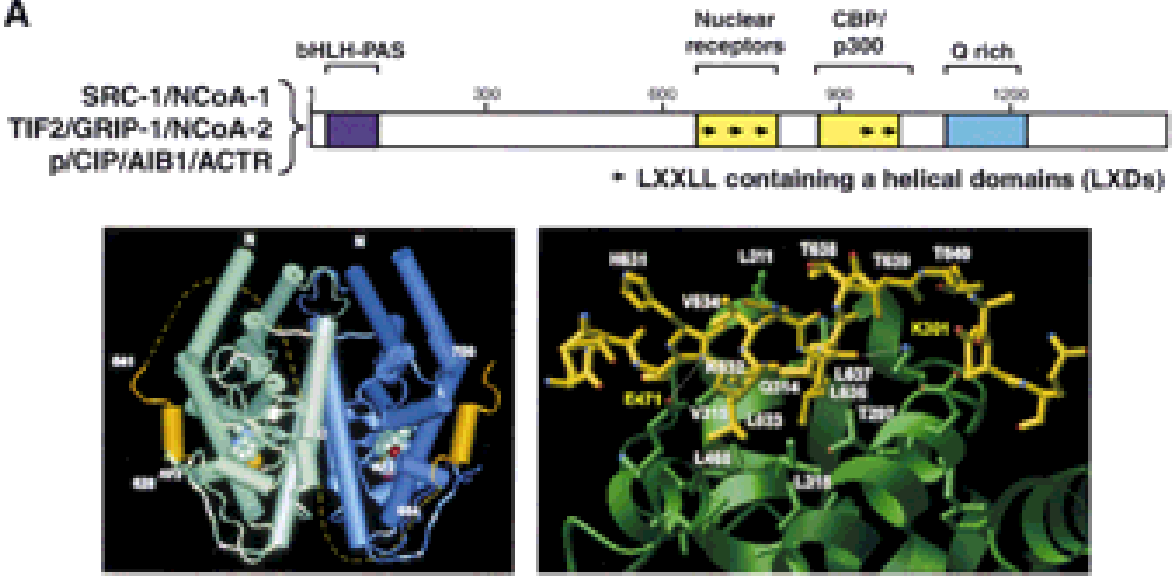

$\mathbf{B}$
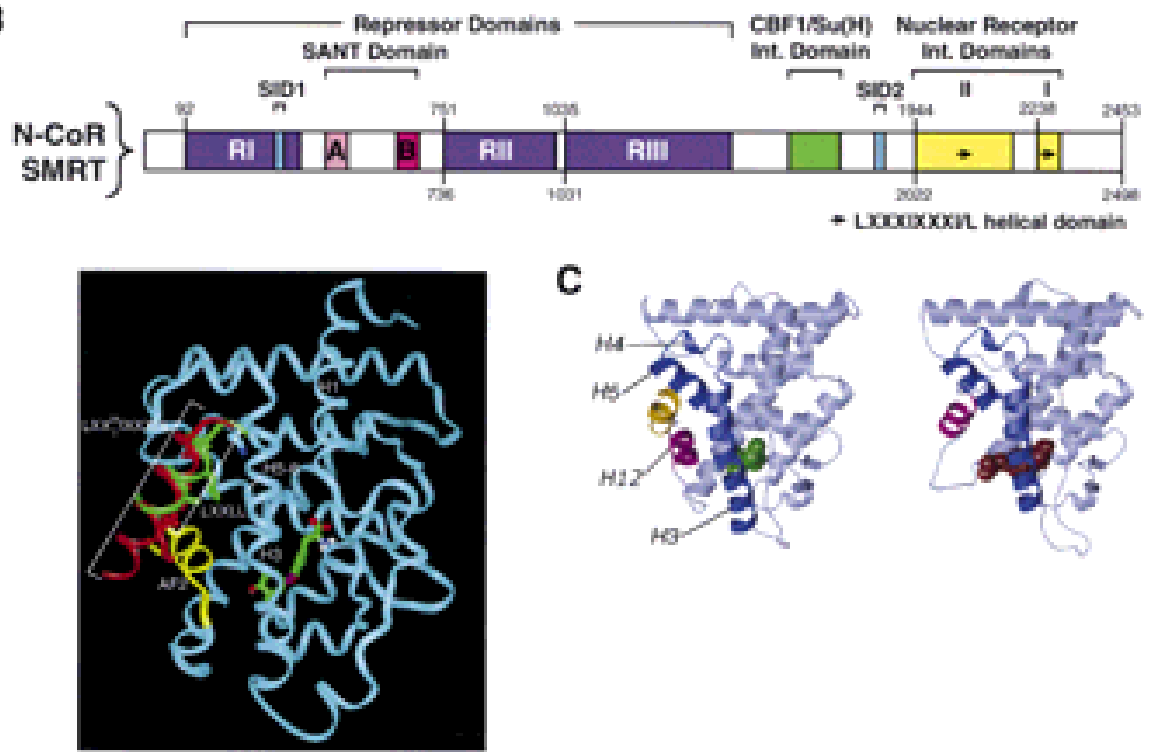

C
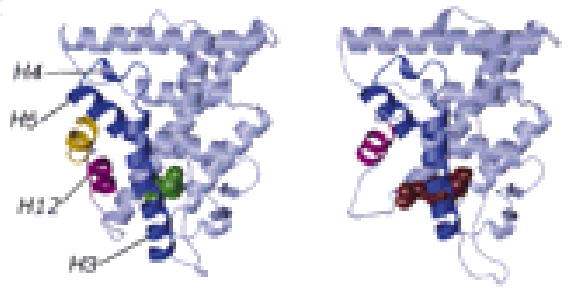

D
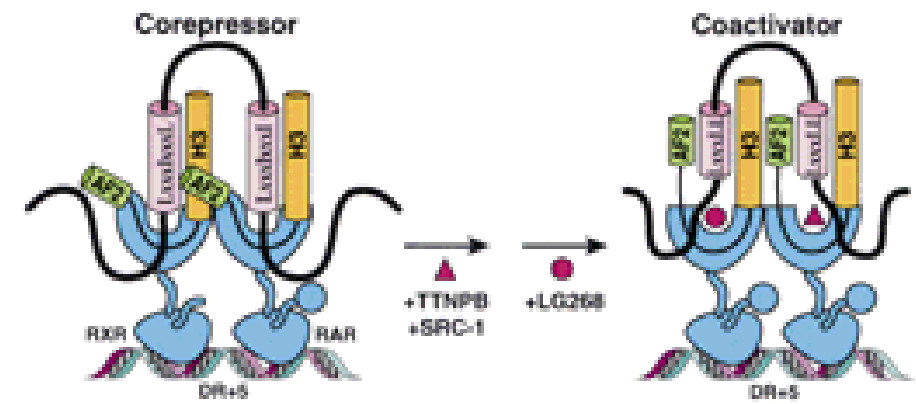

Figure 4. Coactivator and corepressor receptor interaction motifs. (A) Domain structures of members of the SRC-1/p160 family. LXXLL motifs within the NR and CBP-interaction domains are indicated by asterisks. (Left) Crystal structure of the ternary complex of a PPAR $\gamma$ LBD dimer (blue and cyan) in association with the activating ligand rosiglitazone and a 66-amino acid peptide (yellow) containing LXXLL motifs 1 and 2 (cylinder) from SRC-1. The dotted line represents a relatively disordered linker region of the peptide. The structure illustrates the ability of two LXXLL motifs from the same SRC-1 molecule to dock to each component of the dimer. (Right) Interactions of the LXXLL motif with the PPAR $\gamma$ ligand binding domain. The LXXLL helix is presented as a stick model, with the PPAR $\gamma$ LBD shown as a ribbon diagram. Glutamine 471 in the AF-2 domain of PPAR $\gamma$ and lysine 301 in helix 3 form a charge-clamp that grips the ends of the LXXLL helix. The leucine residues of the LXXLL motif packed within a hydrophobic cavity between the charge clamp (Adapted from Nolte et al. 1998 with permission). (B) Domain structures of $\mathrm{NCoR}$ and SMRT. carboxy-terminal domains I and II mediate NR interactions. RI, RII, and RIII represent domains that harbor intrinsic repression activity when tethered to the DNA binding domain of GAL4. The two interaction domains harbor an extended LXX IXX I/L helix, which binds to the hydrophobic coactivator pocket without need for the change-clamp. (C) (Left) Structure of the ER LBD in the presence of agonist diethylstilbestrol (DES) or antagonist and an LXXLL peptide derived from GRIP-1 (Le Douarin et al. 1995). DES is buried deep within a central cavity and makes contact with the helix 12 (gold) and contains the AF-2 motif. The LXXLL peptide is bound to a hydrophobic pocket located between helix 12 and the end of helix 3. (Right) With the ER LBD bound to OHT, the overall fold of the LBD is similar, with OHT occupying the same binding site as DES. However, the OHT sidechain alters the position of helix 12, such that it occludes the LXXLL binding pocket. (Adapted from Shiau, et al. 1998, with permission. $D$ Model for the exchange of a N-CoR with SRC-1/CBP coactivator complex. DNA-bound NRs form ligand-dependent interactions with N-CoR via ligand-independent interactions with two LXXX IXXX I/L motifs. Ligand-dependent binding of coactivator factors depends on recruitment via the LXXLL helix.

grounds, the zinc finger transcription factor Swi5p was found, after transport to the nucleus, to bind to the URS-1 of the HO promoter at the end of anaphase (Cosma et al. 1999). This factor then recruited the SWI/
SNF complex, with subsequent recruitment of the SAGA complex, which facilitated binding of the transcription factor SBF (Swi 4/6). Intriguingly, Swi5p remains at the $H O$ promoter only briefly, $\sim 5$ minutes. 
However, the persistence of SWI/SNF and SAGA complexes on $H O$ was self sustaining, proposed to constitute an "epigenetic memory" of the transient occupation of $H O$ by Swi5p. There is a corresponding cell cycle regulation of histone acetylation at the $\mathrm{HO}$ locus (Krebs et al. 1999). Interestingly, the corepressor Ash1p (Sil and Herskowitz 1996) selectively accumulates in daughter cells and aborts recruitment of SWI/SNF, SAGA and SBF, providing, at least in part, a molecular explanation for the mating-type switch event.

In considering the various activities of complexes involved in NR function, it is conceivable that chromatin remodeling complexes and complexes containing HAT activities are recruited to the promoter initially. These factors may relieve the repressive actions of chromatin, analogous to the SWI/SNF and SAGA complexes, and set the stage for a second chromatin-dependent step of gene activation requiring factors with HAT activity, HMG proteins, and other factors. Finally, these factors may require the actions of additional complexes that include TRAP/DRIP/ARC. Indeed, a release of CBP and p160s late in RAR-dependent promoter activation has been suggested (Chen et al. 1999b), supporting a potential turnover of complexes during or at the conclusion of activation events.

In broad outline, one could propose a model for transcriptional activation by NRs that closely parallel that for transcriptional activation in yeast. It is pertinent to note, however, that NRs, CBP/p300, and SRC family members are not present in yeast. We suggest that during metazoan development, the developmental and physiologic demands of multicellular organisms required the evolution of other classes of specialized transcription factors and corresponding coactivator complexes. This large number of complexes allows for a combinatorial overlay on the sequential events required for gene activation, in which different complexes are essential for appropriate spatial and temporal patterns of gene expression.

\section{Cell and promoter-specific coactivators}

Recent studies suggest that cell-specific coactivators may also play critical roles in gene-specific transcriptional activation. For example, peroxisome proliferatoractivated receptor $\gamma(\operatorname{PPAR} \gamma)$ can activate transcription of the uncoupling protein 1 (UCP-1) gene in brown fat but not in fibroblasts. Investigation of the basis for this specificity led to the identification of PGC-1 (PPAR $\gamma$ coactivator-1) (Puigserver et al. 1998), which is expressed specifically in brown fat and skeletal muscle and is markedly upregulated by exposure to cold. PGC-1 binds to PPAR $\gamma$ and enables it to activate the UCP-1 gene in fibroblasts. Although these findings suggest that PGC-1 is a cell-specific coactivator necessary for activation of $U C P-1$ and perhaps other genes involved in adaptive thermogenesis, the molecular basis for the requirement of PGC-1 in activation of the UCP-1 gene is unknown, nor is the basis of its promoter-specificity. As SRC-1 and $\mathrm{CBP}$ are also required for activation of this gene by
PPAR $\gamma$, a critical question is why PGC-1 serves promoter-specific activator functions (Fig. 4A).

A number of coactivators have been identified that exhibit relative preferences for a subset of NRs. For example, ARA70 (androgen receptor coactivator 7) is reported to enhance androgen receptor function in transfected cell lines (Yeh and Chang 1996; Miyamoto et al. 1998). Another particularly interesting example is SRA, which activates the AF-1 function of steroid hormone receptors (Lanz et al. 1999). Although identified in a yeast two-hybrid screen, this factor has proven to function as an RNA molecule. SRA can interact and synergize with SRC1 in activation of specific steroid hormone receptors.

\section{Transrepression by NRs}

Activation of a NR could alter the expression of a component of a signal transudation pathway that exerts a negative effect. The GR has been demonstrated to inhibit NFкB function in lymphocytes, in part, by upregulating the expression of the inhibitory factor IкB $\beta$ (Auphan et al. 1995). Many cases of transrepression are reciprocal, however. One of the best-documented examples of mutual transrepression is the reciprocal antagonistic effect of NRs and AP-1 factors, initially documented for the GR (Fig. 2D) (Jonat et al. 1990) and confirmed for other receptors (Yang-Yen et al. 1990; Schule et al. 1991). Activation of the GR blunts the response of an AP-1-dependent promoter to phorbol ester or Ras stimulation. Conversely, activation of AP-1 inhibits transcriptional responses of GR-dependent genes to glucocorticoids. Intriguingly, transcription units that harbor adjacent DNA binding sites for both factors in promoters/enhancers often exhibit synergy rather than transrepression.

Several lines of evidence suggest that competition for limiting coactivator proteins in the nucleus accounts for at least some aspects of transrepression (Kamei et al. 1996). CBP and p300 appear in the available assays to in some way be limiting and quantitatively important in actions of the NRs and many other signal-dependent transcription factors. Overexpression of CBP or p300 has been shown to alleviate mutual transrepression of NRs and AP-1 in cell-based assays (Kamei et al. 1996), although there may be other limiting components. Genetic evidence further suggests the hypothesis that CBP and p300 are functionally limiting (Tanaka et al. 1997). Animals heterozygous for null alleles of either CBP or p300 exhibit haploinsufficiency phenotypes and compound heterozygotes die in utero (Tanaka et al. 1997; Yao et al. 1998). In contrast to direct activation of target genes, which requires hundreds to thousands of receptors per cell, transrepression is most often observed in situations in which the receptor number is much higher, consistent with the idea that this mechanism of transcriptional inhibition might in some cases reflect sequestration of coactivators, perhaps locally.

The role of transrepression is documented most rigorously by elegant gene replacement experiments in vivo, 
which demonstrate that the transrepression activity of the GR appears to account for a significant component of its in vivo biological function. Mice in which the GR has been knocked out die prematurely as a result of a failure of lung maturation (Cole et al. 1995). In contrast, when a point mutation is introduced into the GR DNA-binding domain that abolishes high-affinity recognition of specific glucocorticoid response elements, but did not eliminate transrepression, the animals survived (Reichardt et al. 1998). Thus, the defect in lung maturation was rescued by a GR that is unable to activate direct target genes but retains the ability to transrepress.

\section{Active repression by NRs}

The ability of the TR and RARs to inhibit gene expression in the absence or in the presence of ligand raises a series of intriguing issues. In some cases, repressive effects may be do to passive inhibition, which can occur due to competition for DNA sites with other, stronger transactivators or formation of heterodimer pairs that are transcriptionally inactive. In addition, many NRs have been demonstrated to inhibit gene expression in a ligand-dependent manner by the previously described phenomenon of transrepression, which in part involves competition for limiting coactivator complexes (Fig. 1). Most consideration has been given to the molecular mechanisms by which unliganded or antagonist-bound NRs mediate active repression on binding to response elements in target genes, or agonist-dependent repression on negative response elements.

Because maximal repression by unliganded TR required domains not involved in inhibitory TFIIB interactions (Baniahmad et al. 1993; Sauer et al. 1995) a search for additional proteins that mediated these effects led to identification of a factor of $\sim 270 \mathrm{kD}$ that associated with unliganded TR and RARs. This led to cloning of N-CoR (NR corepressor) (Hörlein et al. 1995; Kurokawa et al. 1995), a portion of which had been isolated previously in a yeast two-hybrid screen as RIP13 (Lee et al. 1995b), and the highly related factor, SMRT (silencing mediator for retinoic acid and thyroid hormone receptors) (Chen and Evans 1995), or TRAC2 (T3 associated cofactor) (Sande and Privalsky 1996), both $\sim 270 \mathrm{kDa}$ (Ordentlich et al. 1999; Park et al. 1999) (Fig. 5B). Both N-CoR and SMRT contain a conserved bipartite NR interaction domain (Seol et al. 1996; Zamir et al. 1996; Li et al. 1997b). Ligand binding causes decreased interaction of N-CoR to TR and RAR on most DNA sites in both biochemical assays (Horlein et al. 1995; Kurokawa et al. 1995), and intact cells (Perissi et al. 1999b). N-CoR also interacts with, and serves as a corepressor for Rev ERB (Zamir et al. 1996), COUP transcription factors (Shibata et al. 1997), and DAX1 (Crawford et al. 1998). N-CoR has also been proposed to serve as a coactivator on some promoters harboring "negative" T3 repressor elements, such as TSH $\beta$ (Tagami et al. 1997), but there is no rigorous evidence for this model.

Both N-CoR and SMRT contain a highly related amino-terminal region and at least three independent re- pressor domains that are capable of transferring active repression to a heterologous DNA binding domain (Chen and Evans 1995; Horlein et al. 1995). N-CoR and SMRT interact with mammalian homologes of proteins that have been defined genetically in yeast to mediate transcriptional repression (guilt by association). Thyroid hormone-resistance syndromes can be correlated with mutations in the LBD of TR $\beta$ that enhance ligand-independent interactions anti N-CoR/SMRT (Yoh et al. 1997). Nuclear microinjection of anti-N-CoR antibodies blocks active repression by the TR in cells (Heinzel et al. 1997). Intriguingly, the recruitment of NCoR or SMRT appears to be essential for the antagonist activity of ER and PR antagonists (Jackson et al. 1997; Smith et al. 1997; Lavinsky et al. 1998), potentially by blocking function of the constitutive AF-1 transactivation domain.

There are a few well-documented examples in which the transcriptional responses of the TR to ligand appear to be reversed, that is, the apo receptor activates transcription whereas addition of ligand results in repression. For example, thyroid hormone represses transcription from the thyroid stimulating hormone $\beta$ (TSH $\beta$ ) promoter and this effect appears to involve TR binding sites (Darling et al. 1989). Similarly, a thyroid hormone response element (TRE) in the Rous sarcoma virus (RSV) promoter is activated by unliganded TR and this effect is reversed by thyroid hormone (Saatcioglu et al. 1993). In the context of the TSH $\beta$ promoter, it has been suggested that the binding of N-CoR to the TR results in transactivation rather than repression (Tagami et al. 1997). Initial insights into the molecular mechanisms for such a switch in ligand-dependent transcriptional function has been obtained by evidence of recruitment of in $\mathrm{mSin} 3$ and HDAC2 onto the liganded receptor on a negative TRE, perhaps reflecting binding of receptor homodimers, rather than RAR-RXR heterodimers, on this site (Sasaki et al. 1999).

The potential roles of N-CoR and SMRT as corepressors have been extended to numerous factors unrelated to NRs, suggesting that they play more general roles in the regulation of gene expression. N-CoR has been shown to be essential for transcriptional repression by Mad, a HLH factor that forms heterodimers with Max (Heinzel et al. 1997). SMRT has recently been found to interact with CBF-1/RBP-JK, a mammalian homolog of suppressor of hairless (Kao et al. 1998). CBF-1/RBP-JK is a repressor that is converted to an activator by binding to a fragment of the cytoplasmic domain of Notch (Kao et al. 1998). The repressor activity of CBF-1/RBP-JK has recently been suggested to depend on interaction with SMRT, with conversion of CBF-1/RBP-JK from a repressor to an activator postulated to result from displacement of SMRT by the cytoplasmic domain of Notch. $\mathrm{N}-\mathrm{CoR}$ and SMRT also associate with homeodomain repressors such as Rpx and can bind to other homeodomain factors, such as Pit-1, modulating its activity (Xu et al. 1998). Thus, N-CoR/SMRT may play important roles in the regulation of homeodomain repressor function.

Indeed, in concert with the observation that active repression of gene expression by sequence-specific tran- 
Figure 5. Integration of nuclear signaling events by coactivator and corepressor complexes. At the bottom of the figure, ligands are illustrated to regulate the association of coactivator and corepressor complexes with ligand-dependent nuclear receptors. The interactions of these complexes with nuclear receptors may also be regulated by other SRC-1 signal transduction systems, such as protein $A$ and MAP kinase-dependent signaling events, which may target either the coactivator or corepressor complexes themselves, or the nuclear receptor. This is demonstrated in the case of $E R \alpha, E R \beta$ and a similar idea is the switch of WT-1 and Dax-1.

scription factors plays critical roles in the regulation of diverse biological processes, including cell proliferation, development, and homeostasis, there appears to be multiple mediators of active repression. In Drosophila, for example, a series of sequence-specific repressors are essential for establishing spatially defined patterns of cellspecific gene expression, referred to as long range or short range repressors, based on the distance over which they exert their effects (Gray and Levine 1996; Sauer et al. 1996; Mannervik et al. 1999). A critical question is whether or not the cofactors mediating these two types of repression are distinct. Several suggestions as to the mechanisms responsible for long and short-range repression have been offered. Based on the identification of Groucho as a repressor for the bHLH factor Hairy required for neurogenesis and segmentation, physical interaction could be demonstrated for many of the Drosophila repressors (Aronson et al. 1997; Lee and Young 1998), most of which have been established as long-range repressors (Cai et al. 1996). Because of homology to the yeast repressor, TUP1, which has been postulated to in- hibit RNA pol II complex function by nucleosomal positioning over the core promoter (Herschbach et al. 1994; Edmondson et al. 1996; Treitel et al. 1998), a link between transcription factors mediating repression and the recruitment of a complex that can function at core, can be suggested.

In addition, regulatory control of Groucho-mediated repression has been suggested in Drosophila. The DNAbinding function of dTCF has been shown to be a distal component of the Wingless signaling pathway (Siegfried and Perrimon 1994; Cox and Peifer 1998). dTCF binds Groucho in the absence of the Wg signal, which is displaced upon nuclear translocation of $\beta$-catenin (Cavallo et al. 1997, 1998; Chawla et al. 1998). CBP acetylates the amino terminus of $\mathrm{dTCF}$, which is required for target gene activation, and permits the binding of $\beta$-catenin (Waltzer and Bienz 1998). A second class of repressors was identified based on binding the E1A carboxyl terminus (Schaeper et al. 1995) referred to as dCtBP (Nibu et al. 1998a,b; Poortinga et al. 1998). Because the patterning defects in dCtBP mutant embryos, resemble those of 
Snail and Knirps (Nibu et al. 1998a), which have been described as short-range repressors, dCtBP may interact with a series of Drosophila repressors that exert roles as mediators of short-range repression.

\section{Recruitment of Sin3-histone deacetylase complexes}

Critical insights into the potential mechanisms of transcriptional repression by NRs were provided by the discovery of mammalian homologs of yeast Sin 3 (Ayer et al. 1995; Schreiber-Agus et al. 1995) and the subsequent finding that these proteins interact with $\mathrm{N}-\mathrm{CoR}$ and SMRT (Nagy et al. 1987; Alland et al. 1997; Heinzel et al. 1997). The yeast and mammalian Sin 3 proteins are components of corepressor complexes that also contain histone deacetylases (RPD3 in yeast or HDAC1/HDAC2 in mammals) (Vidal et al. 1991; Taunton et al. 1996; Alland et al. 1997; Hassig et al. 1997; Heinzel et al. 1997; Kadosh and Struhl 1997; Laherty et al. 1997; Nagy et al. 1997; Zhang et al. 1997). These findings therefore suggested a remarkable biochemical and enzymatic symmetry to the transition between repressed and activated states of transcription, in which the recruitment of complexes with HAT activity provides a critical step in the process of transcriptional activation, whereas the recruitment of complexes with HDAE activity provides a critical step in active repression. In this regard, complexes with HAT activity and HDAC activity are conserved from yeast to mammals and appear to play general roles in the control of transcriptional activation. However, like NRs and the SRC-1 family of coactivators, proteins homologous to N-CoR and SMRT are not encoded by the yeast genome. These proteins therefore appear to have arisen during the evolution of metazoan organisms to allow factors such as unliganded NRs and Mad proteins (Alland et al. 1997; Heinzel et al. 1997; Laherty et al. 1997) to mediate transcriptional repression via the Sin3-HDAC pathway. Recently, distinct corepressor domains of N-CoR have been demonstrated to directly interact with other distinct HDAC factors, including HDAC4, HDAC5, and HDAC7, implying a redundant or combinatorial deacetylase-dependent code of repression (Huang et al. 2000; Kao et al. 2000).

Immunohistochemical and biochemical studies suggest that N-CoR and SMRT are not stable stoichiometric components of Sin 3 corepressor complexes (Soderstrom et al. 1997; Zhang et al. 1998b). Purification of a murine Sin3 complex resulted in copurification of the histone binding protein $\mathrm{RbAp} 46$, RbAp 48, HDAC1, HDAC2, and two small proteins SAP30 and SAP18 (Zhang et al. 1997; Laherty et al. 1998). Intriguingly, with the isolation of full-length SMRT (Ordentlich et al. 1999; Park et al. 1999), it is now clear that they are likely to share all functional domains, including an amino-terminal domain sequence that interacts with the mammalian homolog of Seven-in-absentia (Siah); this region of N-CoR imparts a decreased half life, and this links its regulation to the 26S proteosome/ubiquitination pathway (Zhang et al. 1998c).

As in the case of coactivators, there are numerous other potential corepressors. Thus, the TR uncoupling protein (Burris et al. 1995) and Sun-CoR (Zamir et al. 1997) may serve specific roles. In addition, the TIF-1 factors (Le Douarin et al. 1996; Moosmann et al. 1996) that interact with NRs via LXXLL (see below) motifs can bind to the Mod-1/Mod-2 factors (Le Douarin et al. 1996), which bind to SNF2- $\beta$. Recently, an intrinsic protein kinase function has been suggested for TIF1- $\alpha$ (Fraser et al. 1998). The most perplexing aspect is the biochemical mechanism that allows the assembly of N-CoR/SMRT/ HDAC and Sin3 complexes, and potentially other classes of corepressors. Indeed, many DNA-binding transcription factors may bind either a Groucho ortholog, CtBP, or N-CoR/SMRT. Furthermore DNA sequences may recruit corepressors and adjudicate the strength of corepressor action. SAP30, which was isolated independently in a yeast two-hybrid screen with $\mathrm{mSin} 3$ (Laherty et al. 1998), is required for a subset of repression events and is conserved from yeast to man. The absence of $\mathrm{N}$ CoR and SMRT as components of these complexes suggests that they either interact only transiently with $\mathrm{mSin} 3$ in cells, or require the recruitment of additional factors to become stable components of these complexes.

\section{Determinants of coactivator and corepressor binding}

Inspection of the amino acid sequences of the NR interaction domains of p160 factors and RIP140 revealed the presence of leucine-rich motifs of the consensus sequence LXXLL, where $\mathrm{L}$ represents leucine and $\mathrm{X}$ any amino acid (Fig. 4A). These motifs were also found to be present in a number of other proteins demonstrated to interact with NRs in a ligand-dependent manner. The LXXLL sequence and a short stretch of amino- and carboxy-terminal amino acids is both necessary and sufficient for ligand-dependent interactions of p160 proteins with NR LBDs (Le Douarin et al. 1995; Heery et al. 1997; Torchia et al. 1997; Ding et al. 1998; Voegel et al. 1998). The concept that LXXLL motifs represent a general structure for NR recognition is supported by the observation that nearly all factors that have been cloned by virtue of their ability to interact with NRs in a liganddependent manner contain one or more copies of this motif. Additional related motifs are found in the CBP/ p300 nuclear receptor interaction domain.

Solving the crystal structures of unliganded and agonist-bound LBDs for several NRs has confirmed the hypothesis that the AF-2 region undergoes a ligand-dependent conformational change (for review, see Moras and Gronemeyer 1998) and permitted evaluation of coactivator and corepressor binding. In the unliganded RXR structure, the AF-2 helix extends away from the ligandbinding domain (Bourguet et al. 1995). In contrast, in the agonist-bound $\operatorname{RAR} \gamma, \operatorname{TR} \alpha, \operatorname{PPAR} \gamma$, and ER LBD structures, the AF-2 helix is tightly packed against the body of the ligand binding domain and makes direct contacts with ligand (Renaud et al. 1995; Wagner et al. 1995; Brzozowski et al. 1997; Shiau et al. 1998) (Fig. 4A,4C). Taken together, these studies are consistent with the 
idea that ligand-dependent changes in the conformation of the AF-2 helix result in the formation of a surface that facilitates coactivator interactions. Intriguingly, the structures of the ER LBD bound to the antagonists raloxifene or dihydroxytamoxifen (OHT) demonstrate a distortion in the position of the AF2 helix (Brzozowski et al. 1997; Shiau et al. 1998) (Fig. 4C). Due to the presence of an additional side chain in these antagonists, the AF-2 helix is unable to pack normally and instead is translated to a position that overlaps with the site of coactivator interaction. These findings suggest that an important aspect of antagonist action is to place the AF-2 helix in a configuration that prevents coactivator binding.

Recent crystal structures indeed demonstrate that the LXXLL motif forms a short $\alpha$ helix (Fig. 4A) (Darimont et al. 1998; Nolte et al. 1998; Shiau et al. 1998). This helix docks to a hydrophobic cleft on the surface of the LBD that is bounded on one side by the AF-2 helix and on the other by the end of helix three. A highly conserved glutamate residue in the AF- 2 domain makes contacts with the amino-terminal end of the LXXLL peptide backbone, while the carboxy-terminal end of the LXXLL helix is held by a conserved lysine residue in helix three. Together, the glutamate and lysine residues form a charge clamp that positions the LXXLL helix to allow the leucine side chains to pack into the intervening hydrophobic cavity (Fig. 4A). These structures suggest that the structural basis of ligand-dependent activation is the closure of the AF-2 helix to form the charge clamp. A critical determinant of coactivator interaction is that the charge clamp grips a helix of the specific length specified by the LXXLL motif and capping end-terminal residues. Although the sequence encompassing the LXXLL motifs is sufficient for NR-coactivator interactions, amino acids amino- and carboxyl terminal to the LXXLL motif appear to make additional contacts with the LBD (Darimont et al. 1998; McInerney et al. 1998). These residues are not conserved among different coactivators and may play roles in determining the specificity of NR-coactivator interaction, possibly specifying which coactivators will bind to a particular NR dimer or heterodimer with highest affinity. These interactions are potentially influenced by structurally distinct physiologic ligands for a particular NR that might induce distinct conformations (McInerney et al. 1998).

Biochemical experiments suggest that two LXXLL motifs from a single p160 protein can interact cooperatively with both subunits of an RAR/RXR or RXR/PPAR heterodimer (Westin et al. 1998). Similarly, a single molecule of SRC-1 containing three LXXLL motifs binds in a highly cooperative manner to the ER LBD /Gee et al. 1999). These findings are supported by the solution of the crystal structure of a dimer of the PPAR $\gamma$ LBD complexed to an SRC-1 peptide containing two LXXLL motifs (Nolte et al. 1998). In this structure, the LXXLL helices interact equivalently with the coactivator binding pockets of both members of the dimer (Fig. 5A). It is also possible that the presence of multiple LXXLL helices within a single coactivator molecule allows for flexibil- ity in complex assembly and/or allows cooperative interactions with adjacent bound transcription factors. Although the amino-terminus of CBP and p300 contains an LXXLL motif and can interact with several NRs in a ligand-dependent manner, effective recruitment of CBP requires additional coactivators, such as p160 factors in the case of DNA-bound RAR/RXR heterodimers (Fig. 4D) (Westin et al. 1998).

Interactions between coactivators and NRs also have recently been suggested to explain the differential responses of permissive and nonpermissive RXR heterodimers to activating ligands. Nonpermissive RXR heterodimers, exemplified by RAR/RXR heterodimers, do not respond to RXR ligands unless the RAR is liganded first (Kurokawa et al. 1994; Forman et al. 1995; Chen et al. 1996). This selective response results from allosteric inhibition of the binding of ligands to RXR that occurs on dimerization and binding to DNA. In contrast, permissive heterodimers, exemplified by PPAR/RXR heterodimers, can be activated independently by RXR or PPAR ligands (Kliewer et al. 1992). Intriguingly, in the case of RAR/RXR heterodimers, an RXR-specific ligand could potentiate only the binding of SRC-1/NCoA-1 in the presence of an RAR-specific ligand (Westin et al. 1998). Molecular modeling of the RAR/RXR heterodimer suggested that in the absence of ligand the AF-2 domain of RXR interact with the LXXLL-binding pocket of RAR. This interaction does not occur when RXR heterodimerizes with a permissive partner, such as PPAR $\gamma$. As the AF-2 domain of NRs forms part of the ligandbinding pocket, its conformation in the context of an unliganded RAR/RXR heterodimer would be predicted to prevent high-affinity binding of RXR ligands and may also enhance the binding of the corepressors NCoR and SMRT. Recruitment of SRC-1 to RAR in response to RAR ligand is proposed to displace the RXR AF-2 domain, enabling RXR to bind to its own specific ligand and interact with a second LXXLL motif of the same SRC-1 molecule. This model provides an explanation for the requirement by the RAR/RXR heterodimer for an RAR-specific ligand for activation, but which can only then be potentiated by an RXR specific ligand (Westin et al. 1998).

In the case of corepressors, the two interaction domains (Chen and Evans 1995; Horlein et al. 1995; Zamir et al. 1997; Hu and Lazar 1999) have proven to contain a conserved sequence (Perissi et al. 1997b; Nagy et al. 1999; Zhu et al. 1999), referred to as the CoRNR box (Zhu et al. 1999) or as a LXXI/HIXXXI/L helix (Perissi et al. 1999b). These reported motifs are predicted to represent extended helices that are required and sufficient to permit binding to unliganded TR and RARs. Based on mapping of the critical receptor residues, this helix appears to bind in the hydrophobic pocket that is occupied by the coactivator LXXLL helical motifs on addition of ligand, but does not depend on the charge clamp formed by the AF-2 helix and helix 3. Because the ligand-activated charge clamp is specific for the length of the coactivator helix, closure on ligand binding would inhibit the binding of corepressor, potentially representing the mo- 
lecular mechanism for ligand-dependent displacement of the corepressor complex. In this model, Ile at position 5 of the extended helix is preferred to Leu, and the presence of an LXXLL motif, in the context of the extended helix abolished interaction. Therefore, it is suggested that the receptor AF-2 helix has evolved to discriminate between the LXXLL helix in coactivators and the extended helix in the N-CoR/SMRT corepressors, permitting the ligand-dependent switch of NR activity (Fig. 4D).

Although the binding of either N-CoR or SMRT to TR and RARs is robust, it is enhanced either by addition of receptor antagonists or the deletion of the AF-2 domain (Chen and Evans 1995; Horlein et al. 1995). Furthermore, whereas unliganded steroid hormone receptors do not appear to interact with N-CoR or SMRT, strong interactions are observed in the presence of antagonists (Vegeto et al. 1992; Lanz and Rusconi 1994; Xu et al. 1996; Jackson et al. 1997; Smith et al. 1997; Cohen et al. 1998; Lavinsky et al. 1998; Wagner et al. 1998; Zhang et al. 1998a). In concert with crystal structures of antagonistbound ERs, these findings indicate that there is an inhibition of N-CoR and SMRT binding by the activation helix of NRs (Fig. 4C). There are receptor-specific differences in the region of the NR interaction domain preferred by each receptors (Lavinsky et al. 1998; Zhang et al. 1998a).

\section{Coregulators as targets of signal transduction pathways}

Signal transduction pathways add another layer of regulation to the functions of coactivator and corepressor complexes (Fig. 5). Phosphorylation events may result in increased or decreased affinity between protein factors, leading to changes in components of the complexes. One example is the SWI/SNF complex, the components of which change at different stages of the cell cycle. In addition, its chromatin remodeling activity depends on the phosphorylation state of some of the subunits, such as Brg1 (Suen et al. 1998), suggesting a mechanism linking cell cycle events and transcription. CBP/p300 can be phosphorylated in vivo (Chrivia et al. 1993) and kinase activities are also found to be associated with CBP/p300 (Nakajima et al. 1996). Thus, it will be informative to investigate if HAT activities or components of $\mathrm{CBP} /$ p300, N-CoAs, and P/CAF complexes are also regulated by the cell cycle in a similar manner. CBP also contains a signal-regulated transcriptional activation domain that is controlled by nuclear calcium and calcium/calmodulin-dependent (Cam) protein kinase IV and by cAMP (Chawla et al. 1998). It is conceivable that such a scenario may also apply to corepressor complexes.

Signal transduction pathways may also influence acetyltransferase functions, and substrate preferences. An example of this has recently been provided by the POU homeodomain transcription factor, Pit-1. Pit-1 controls critical aspects of pituitary development and is positively regulated by the cAMP- and MAP kinase-dependent signal transduction pathways. Antibody microinjection experiments indicate that Pit-1 function requires
CBP/p300 and P/CAF (Xu et al. 1998). Remarkably, stimulation of Pit-1 activity by cAMP requires the HAT activity of CBP, whereas stimulation of Pit-1 activity via the MAP kinase pathway requires the HAT activity of $\mathrm{P} / \mathrm{CAF}$.

Post-transcriptional regulation of coactivation and corepressor complexes will prove to be a critical component of regulated gene transcription. Thus, failure of tamoxifen to mediate regulation of $\mathrm{ER} \alpha$ is reversed by growth factors and cAMP that appear to involve decreased interaction with N-CoR/SMRT (Lavinsky et al. 1998) with enhanced coactivator and decreased N-CoR binding; this can be attributed to a single or amino-terminal residue of the ER. Similarly, MAPK-induced phosphorylation of specific residues on the AF1 domain of ER $\beta$ (Ser-106 and Ser-184) stimulates SRC-1 recruitment (Tremblay et al. 1999) in the presence of partial agonist/ antagonist. The orphan receptor SF-1 responds to MAPKinduced phosphorylation of a single residue (Ser-203), recruiting GRIP1 (Hammer et al. 1999). Negative regulation by amino-terminal phosphorylation has been documented for PPAR $\gamma$ (Hu et al. 1996), apparently decreasing ligand affinity (Shao and Lazar 1999).

\section{Conclusion}

The molecular strategies that underlie regulated gene transcription by NRs appear to involve the combinatorial actions of a large number of coregulators. Together, they establish an activity continuum ranging from active repression to strong gene activation. The effects of other adjacent DNA-bound transcription factors, the DNA binding site, and the array of coregulators together seem to generate recruitment events that set the level of gene activation of repression. Because each component is under transcriptional and post-transcriptional control, the complexity of the coregulatory network itself is likely to underlie the gene-specificity required to meet the demands of developmental and homeostatic gene regulation. We can expect many insights into the detailed molecular mechanisms underlying these events in the next ten years.

\section{Acknowledgments}

We apologize to our colleagues for the many important references that have not been sited or adequately discussed due to space limitations. We thank members of our laboratories for comments and discussions, particularly Dr. Ola Hermanson and Dr. Riki Kurokawa. MGR is an investigator of the Howard Hughes Medical Institute. We acknowledge support from the National Institutes of Health for experiments from our laboratories cited in the manuscript.

\section{References}

Ait-Si-Ali, S., S. Ramirez, F.X. Barre, F. Dkhissi, L. MagnaghiJaulin, J.A. Girault, P. Robin, M. Knibiehler, L.L. Pritchard, B. Ducommun, D. Trouche, and A. Harel-Bellan. 1998. Histone acetyltransferase activity of CBP is controlled by cycle- 
dependent kinases and oncoprotein E1A. Nature 396: 184 186.

Alland, L., R. Muhle, H. Hou, Jr., J. Potes, L. Chin, N. SchreiberAgus, and R.A. DePinho. 1997. Role for N-CoR and histone deacetylase in Sin3-mediated transcriptional repression. $\mathrm{Na}$ ture 387: 49-55.

Anzick, S.L., J. Kononen, R.L. Walker, D.O. Azorsa, M.M. Tanner, X.Y. Guan, G. Sauter, O.P. Kallioniemi, J.M. Trent, and P.S. Meltzer. 1997. AIB1, a steroid receptor coactivator amplified in breast and ovarian cancer. Science 277: 965-968.

Arany, Z., W.R. Sellers, D.M. Livingston, and R. Eckner. 1994. E1A-associated p300 and CREB-associated CBP belong to a conserved family of coactivators. Cell 77: 799-800.

Aronson, B.D., A.L. Fisher, K. Blechman, M. Caudy, and J.P. Gergen. 1997. Groucho-dependent and -independent repression activities of Runt domain proteins. Mol. Cell. Biol. 17: 5581-5587.

Auphan, N., J.A. DiDonato, C. Rosette, A. Helmberg, and M. Karin. 1995. Immunosuppression by glucocorticoids: inhibition of NF- $\kappa$ B activity through induction of I $\kappa$ B synthesis. Science 270: 286-290.

Ayer, D.E., Q.A. Lawrence, and R.N. Eisenman. 1995. Mad-Max transcriptional repression is mediated by ternary complex formation with mammalian homologs of yeast repressor Sin3. Cell 80: 767-776.

Baniahmad, A., I. Ha, D. Reinberg, S. Tsai, M.J. Tsai, and B.W. O'Malley. 1993. Interaction of human thyroid hormone receptor beta with transcription factor TFIIB may mediate target gene derepression and activation by thyroid hormone. Proc. Natl. Acad. Sci. 90: 8832-8836.

Bannister, A.J. and T. Kouzarides. 1996. The CBP co-activator is a histone acetyltransferase. Nature 384: 641-643.

Barnes, J.D., J.L. Crosby, C.M. Jones, C.V. Wright, and B.L. Hogan. 1994. Embryonic expression of Lim-1, the mouse homolog of Xenopus Xlim-1, suggests a role in lateral mesoderm differentiation and neurogenesis. Dev. Biol. 161: 168178.

Baudino, T.A., D.M. Kraichely, S.C. Jefcoat, Jr., S.K. Winchester, N.C. Partridge, and P.N. MacDonald. 1998. Isolation and characterization of a novel coactivator protein, NCoA-62, involved in vitamin D-mediated transcription. J. Biol. Chem. 273: 16434-16441.

Beato, M., P. Herrlich, and G. Schutz. 1995. Steroid hormone receptors: many actors in search of a plot. Cell 83: 851-857.

Blanco, J.C., S. Minucci, J. Lu, X.J. Yang, K.K. Walker, H. Chen, R.M. Evans, Y. Nakatani, and K. Ozato. 1998. The histone acetylase PCAF is a nuclear receptor coactivator. Genes \& Dev. 12: 1638-1651.

Boonyaratanakornkit, V., V. Melvin, P. Prendergast, M. Altmann, L. Ronfani, M.E. Bianchi, L. Taraseviciene, S.K. Nordeen, E.A. Allegretto, and D.P. Edwards. 1998. High-mobility group chromatin proteins 1 and 2 functionally interact with steroid hormone receptors to enhance their DNA binding in vitro and transcriptional activity in mammalian cells. Mol. Cell. Biol. 18: 4471-4487.

Bourguet, W., M. Ruff, P. Chambon, H. Gronemeyer, and D. Moras. 1995. Crystal structure of the ligand-binding domain of the human nuclear receptor RXR- $\alpha$. Nature 375: 377-382.

Brownell, J.E., J. Zhou, T. Ranalli, R. Kobayashi, D.G. Edmondson, S.Y. Roth, and C.D. Allis. 1996. Tetrahymena histone acetyltransferase A: a homolog to yeast Gcn5p linking histone acetylation to gene activation. Cell 84: 843-851.

Brzozowski, A.M., A.C. Pike, Z. Dauter, R.E. Hubbard, T. Bonn, O. Engstrom, L. Ohman, G.L. Greene, J.A. Gustafsson, and M. Carlquist. 1997. Molecular basis of agonism and antago- nism in the oestrogen receptor. Nature 389: 753-758.

Burris, T.P., Z. Nawaz, M.J. Tsai, and B.W. O'Malley. 1995. A nuclear hormone receptor-associated protein that inhibits transactivation by the thyroid hormone and retinoic acid receptors. Proc. Nat1. Acad. Sci. 92: 9525-9529.

Cai, H.N., D.N. Arnosti, and M. Levine. 1996. Long-range repression in the Drosophila embryo. Proc. Natl. Acad. Sci. 93: 9309-9314.

Cairns, B.R., R.S. Levinson, K.R. Yamamoto, and R.D. Kornberg. 1996. Essential role of Swp73p in the function of yeast Swi/Snf complex. Genes \& Dev. 10: 2131-2144.

Cavailles, V., S. Dauvois, P.S. Danielian, and M.G. Parker. 1994. Interaction of proteins with transcriptionally active estrogen receptors. Proc. Natl. Acad. Sci. 91: 10009-10013.

Cavallo, R., D. Rubenstein, and M. Peifer. 1997. Armadillo and dTCF: A marriage made in the nucleus. Curr. Opin. Genet. Dev. 7: 459-466.

Cavallo, R.A., R.T. Cox, M.M. Moline, J. Roose, G.A. Polevoy, H. Clevers, M. Peifer, and A. Bejsovec. 1998. Drosophila Tcf and Groucho interact to repress Wingless signalling activity. Nature 395: 604-608.

Chakravarti, D., V.J. LaMorte, M.C. Nelson, T. Nakajima, I.G. Schulman, H. Juguilon, M. Montminy, and R.M. Evans. 1996. Role of CBP/P300 in nuclear receptor signalling. Nature 383: 99-103.

Chakravarti, D., V. Ogryzko, H.Y. Kao, A. Nash, H. Chen, Y. Nakatani, and R.M. Evans. 1999. A viral mechanism for inhibition of p300 and PCAF acetyltransferase activity. Cell 96: 393-403.

Chambon, P. 1995. The molecular and genetic dissection of the retinoid signaling pathway. Recent Prog. Horm. Res. 50: $317-332$

Chawla, S., G.E. Hardingham, D.R. Quinn, and H. Bading. 1998. CBP: a signal-regulated transcriptional coactivator controlled by nuclear calcium and CaM kinase IV. Science 281: 1505-1509.

Chen, C. and H. Okayama. 1987. High-efficiency transformation of mammalian cells by plasmid DNA. Mol. Cell. Biol. 7: 2745-2752.

Chen, G., J. Fernandez, S. Mische, and A.J. Courey. 1999a. A functional interaction between the histone deacetylase rpd3 and the corepressor groucho in drosophila development. Genes \& Dev. 13: 2218-2230.

Chen, H., R.J. Lin, R.L. Schiltz, D. Chakravarti, A. Nash, L. Nagy, M.L. Privalsky, Y. Nakatani, and R.M. Evans. 1997. Nuclear receptor coactivator ACTR is a novel histone acetyltransferase and forms a multimeric activation complex with P/CAF and CBP/p300. Cell 90: 569-580.

Chen, H., R.J. Lin, W. Xie, D. Wilpitz, and R.M. Evans. 1999b. Regulation of hormone-induced histone hyperacetylation and gene activation via acetylation of an acetylase. Cell 98: 675-686.

Chen, J.D. and R.M. Evans. 1995. A transcriptional co-repressor that interacts with nuclear hormone receptors. Nature 377: 454-457.

Chen, J.Y., J. Clifford, C. Zusi, J. Starrett, D. Tortolani, J. Ostrowski, P.R. Reczek, P. Chambon, and H. Gronemeyer. 1996. Two distinct actions of retinoid-receptor ligands. $\mathrm{Na}$ ture 382: 819-822.

Chiba, H., M. Muramatsu, A. Nomoto, and H. Kato. 1994. Two human homologues of Saccharomyces cerevisiae SWI2/ SNF2 and Drosophila brahma are transcriptional coactivators cooperating with the estrogen receptor and the retinoic acid receptor. Nucleic Acids Res. 22: 1815-1820.

Chrivia, J.C., R.P. Kwok, N. Lamb, M. Hagiwara, M.R. Montminy, and R.H. Goodman. 1993. Phosphorylated CREB 
binds specifically to the nuclear protein CBP. Nature 365: 855-859.

Clements, A., J.R. Rojas, R.C. Trievel, L. Wang, S.L. Berger, and R. Marmorstein. 1999. Crystal structure of the histone acetyltransferase domain of the human PCAF transcriptional regulator bound to coenzyme A. EMBO J. 18: 35213532.

Cohen, R.N., F.E. Wondisford, and A.N. Hollenberg. 1998. Two separate NCoR (nuclear receptor corepressor) interaction domains mediate corepressor action on thyroid hormone response elements. Mol. Endocrinol. 12: 1567-1581.

Cole, T.J., J.A. Blendy, A.P. Monaghan, K. Krieglstein, W. Schmid, A. Aguzzi, G. Fantuzzi, E. Hummler, K. Unsicker, and G. Schutz. 1995. Targeted disruption of the glucocorticoid receptor gene blocks adrenergic chromaffin cell development and severely retards lung maturation. Genes \& Dev. 9: $1608-1621$.

Cosma, M.P., T. Tanaka, and K. Nasmyth. 1999. Ordered recruitment of transcription and chromatin remodeling factors to a cell cycle- and developmentally regulated promoter. Cell 97: 299-311.

Cox, R.T. and M. Peifer. 1998. Wingless signaling: The inconvenient complexities of life. Curr. Biol. 8: R140-144.

Crawford, P.A., C. Dorn, Y. Sadovsky, and J. Milbrandt. 1998. Nuclear receptor DAX-1 recruits nuclear receptor corepressor N-CoR to steroidogenic factor 1. Mol. Cell. Biol. 18: $2949-2956$.

Danielian, P.S., R. White, J.A. Lees, and M.G. Parker. 1992. Identification of a conserved region required for hormone dependent transcriptional activation by steroid hormone receptors. EMBO J. 11: 1025-1033.

Darimont, B.D., R.L. Wagner, J.W. Apriletti, M.R. Stallcup, P.J. Kushner, J.D. Baxter, R.J. Fletterick, and K.R. Yamamoto. 1998. Structure and specificity of nuclear receptor-coactivator interactions. Genes \& Dev. 12: 3343-3356.

Darling, D.S., J. Burnside, and W.W. Chin. 1989. Binding of thyroid hormone receptors to the rat thyrotropin- $\beta$ gene. Mol. Endocrinol. 3: 1359-1368.

Di Croce, L., R. Koop, P. Venditti, H.M. Westphal, K.P. Nightingale, D.F. Corona, P.B. Becker, and M. Beato. 1999. Twostep synergism between the progesterone receptor and the DNA- binding domain of nuclear factor 1 on MMTV minichromosomes. Mol. Cell 4: 45-54.

Ding, X.F., C.M. Anderson, H. Ma, H. Hong, R.M. Uht, P.J. Kushner, and M.R. Stallcup. 1998. Nuclear receptor-binding sites of coactivators glucocorticoid receptor interacting protein 1 (GRIP1) and steroid receptor coactivator 1 (SRC- 1): multiple motifs with different binding specificities. Mol. Endocrinol. 12: 302-313.

Dingwall, A.K., S.J. Beek, C.M. McCallum, J.W. Tamkun, G.V. Kalpana, S.P. Goff, and M.P. Scott. 1995. The Drosophila snrl and brm proteins are related to yeast SWI/SNF proteins and are components of a large protein complex. Mol. Biol. Cell. 6: 777-791.

Durand, B., M. Saunders, C. Gaudon, B. Roy, R. Losson, and P. Chambon. 1994. Activation function 2 (AF-2) of retinoic acid receptor and 9-cis retinoic acid receptor: presence of a conserved autonomous constitutive activating domain and influence of the nature of the response element on AF-2 activity. $E M B O ~ J . ~ 13: 5370-5382$.

Eckner, R., M.E. Ewen, D. Newsome, M. Gerdes, J.A. DeCaprio, J.B. Lawrence, and D.M. Livingston. 1994. Molecular cloning and functional analysis of the adenovirus E1A-associated $300-\mathrm{kD}$ protein $(\mathrm{p} 300)$ reveals a protein with properties of a transcriptional adaptor. Genes \& Dev. 8: 869-884.

Edmondson, D.G., M.M. Smith, and S.Y. Roth. 1996. Repres- sion domain of the yeast global repressor Tup1 interacts directly with histones $\mathrm{H} 3$ and H4. Genes \& Dev. 10: 12471259.

Fletcher, T.M. and J.C. Hansen. 1996. The nucleosomal array: structure/function relationships. Crit. Rev. Eukaryot. Gene Expr. 6: 149-188.

Fondell, J.D., F. Brunel, K. Hisatake, and R.G. Roeder. 1996a. Unliganded thyroid hormone receptor $\alpha$ can target TATAbinding protein for transcriptional repression. Mol. Cell. Biol. 16: 281-287.

Fondell, J.D., H. Ge, and R.G. Roeder. 1996b. Ligand induction of a transcriptionally active thyroid hormone receptor coactivator complex. Proc. Nat1. Acad. Sci. 93: 8329-8333.

Fondell, J.D., M. Guermah, S. Malik, and R.G. Roeder. 1999. Thyroid hormone receptor-associated proteins and general positive cofactors mediate thyroid hormone receptor function in the absence of the TATA box-binding proteinassociated factors of TFIID. Proc. Natl. Acad. Sci. 96: 19591964.

Forman, B.M., K. Umesono, J. Chen, and R.M. Evans. 1995. Unique response pathways are established by allosteric interactions among nuclear hormone receptors. Cell 81: 541550.

Fraser, R.A., D.J. Heard, S. Adam, A.C. Lavigne, B. Le Douarin, L. Tora, R. Losson, C. Rochette-Egly, and P. Chambon. 1998. The putative cofactor TIF $1 \alpha$ is a protein kinase that is hyperphosphorylated upon interaction with liganded nuclear receptors. J. Biol. Chem. 273: 16199-16204.

Fryer, C.J. and T.K. Archer. 1998. Chromatin remodelling by the glucocorticoid receptor requires the BRG1 complex. Nature 393: 88-91.

Gee, A.C., K.E. Carlson, P.G. Martini, B.S. Katzenellenbogen, and J.A. Katzenellenbogen. 1999. Coactivator peptides have a differential stabilizing effect on the binding of estrogens and antiestrogens with the estrogen receptor. Mol. Endocrinol. 13: 1912-1923.

Grant, P.A., L. Duggan, J. Cote, S.M. Roberts, J.E. Brownell, R. Candau, R. Ohba, T. Owen-Hughes, C.D. Allis, F. Winston, S.L. Berger, and J.L. Workman. 1997. Yeast Gcn5 functions in two multisubunit complexes to acetylate nucleosomal histones: characterization of an Ada complex and the SAGA (Spt/Ada) complex. Genes \& Dev. 11: 1640-1650.

Grant, P.A., D. Schieltz, M.G. Pray-Grant, D.J. Steger, J.C. Reese, J.R. Yates, 3rd, and J.L. Workman. 1998a. A subset of TAF(II)s are integral components of the SAGA complex required for nucleosome acetylation and transcriptional stimulation. Cell 94: 45-53.

Grant, P.A., D. Schieltz, M.G. Pray-Grant, J.R. Yates, 3rd, and J.L. Workman. 1998b. The ATM-related cofactor Tral is a component of the purified SAGA complex. Mol. Cell 2: 863867.

Gray, S. and M. Levine. 1996. Transcriptional repression in development. Curr. Opin. Cell. Biol. 8: 358-364.

Gu, W., S. Malik, M. Ito, C.X. Yuan, J.D. Fondell, X. Zhang, E. Martinez, J. Qin, and R.G. Roeder. 1999. A novel human SRB/MED-containing cofactor complex, SMCC, involved in transcription regulation. Mol. Cell 3: 97-108.

Halachmi, S., E. Marden, G. Martin, H. MacKay, C. Abbondanza, and M. Brown. 1994. Estrogen receptor-associated proteins: possible mediators of hormone- induced transcription. Science 264: 1455-1458.

Hamamori, Y., V. Sartorelli, V. Ogryzko, P.L. Puri, H.Y. Wu, J.Y. Wang, Y. Nakatani, and L. Kedes. 1999. Regulation of histone acetyltransferases p300 and PCAF by the bHLH protein twist and adenoviral oncoprotein E1A. Cell 96: 405-413.

Hammer, G.D., I. Krylova, Y. Zhang, B.D. Darimont, K. Simp- 
son, N.L. Weigel, and H.A. Ingraham. 1999. Phosphorylation of the nuclear receptor SF-1 modulates cofactor recruitment: integration of hormone signaling in reproduction and stress. Mol. Cell 3: 521-526.

Hampsey, M. and D. Reinberg. 1999. RNA polymerase II as a control panel for multiple coactivator complexes. Curr. Opin. Genet. Dev. 9: 132-139.

Hanstein, B., R. Eckner, J. DiRenzo, S. Halachmi, H. Liu, B. Searcy, R. Kurokawa, and M. Brown. 1996. p300 is a component of an estrogen receptor coactivator complex. Proc. Natl. Acad. Sci. 93: 11540-11545.

Hassig, C.A., T.C. Fleischer, A.N. Billin, S.L. Schreiber, and D.E. Ayer. 1997. Histone deacetylase activity is required for full transcriptional repression by $\mathrm{mSin} 3 \mathrm{~A}$. Cell 89:341347.

Hecht, A., T. Laroche, S. Strahl-Bolsinger, S.M. Gasser, and M. Grunstein. 1995. Histone H3 and H4 N-termini interact with SIR3 and SIR4 proteins: a molecular model for the formation of heterochromatin in yeast. Cell 80: 583-592.

Heery, D.M., E. Kalkhoven, S. Hoare, and M.G. Parker. 1997. A signature motif in transcriptional co-activators mediates binding to nuclear receptors. Nature 387: 733-736.

Heinzel, T., R.M. Lavinsky, T.M. Mullen, M. Soderstrom, C.D. Laherty, J. Torchia, W.M. Yang, G. Brard, S.D. Ngo, J.R. Davie, E. Seto, R.N. Eisenman, D.W. Rose, C.K. Glass, and M.G. Rosenfeld. 1997. A complex containing N-CoR, mSin3 and histone deacetylase mediates transcriptional repression. Nature 387: 43-48.

Herschbach, B.M., M.B. Arnaud, and A.D. Johnson. 1994. Transcriptional repression directed by the yeast alpha 2 protein in vitro. Nature 370: 309-311.

Hong, H., K. Kohli, M.J. Garabedian, and M.R. Stallcup. 1997. GRIP1, a transcriptional coactivator for the AF-2 transactivation domain of steroid, thyroid, retinoid, and vitamin D receptors. Mol. Cell. Biol. 17: 2735-2744.

Horlein, A.J., A.M. Naar, T. Heinzel, J. Torchia, B. Gloss, R. Kurokawa, A. Ryan, Y. Kamei, M. Soderstrom, C.K. Glass, and et al. 1995. Ligand-independent repression by the thyroid hormone receptor mediated by a nuclear receptor corepressor. Nature 377: 397-404.

Hu, E., J.B. Kim, P. Sarraf, and B.M. Spiegelman. 1996. Inhibition of adipogenesis through MAP kinase-mediated phosphorylation of PPAR $\gamma$. Science 274: 2100-2103.

$\mathrm{Hu}, \mathrm{X}$. and M.A. Lazar. 1999. The CoRNR motif controls the recruitment of corepressors by nuclear hormone receptors. Nature 402: 93-96.

Huang, E.Y., J. Zhang, E.A. Miska, M.G. Guenther, T. Kouzarides, and M.A. Lazar. 2000. Nuclear receptor corepressors partner with class II histone deacetylases in a Sin3-independent repression pathway. Genes \& Dev. 14: 45-54.

Huibregtse, J.M., M. Scheffner, S. Beaudenon, and P.M. Howley. 1995. A family of proteins structurally and functionally related to the E6-AP ubiquitin-protein ligase. Proc. Natl. Acad. Sci. 92: 5249.

Ichinose, H., J.M. Garnier, P. Chambon, and R. Losson. 1997. Ligand-dependent interaction between the estrogen receptor and the human homologues of SWI2/SNF2. Gene 188: 95100.

Imhof, M.O. and D.P. McDonnell. 1996. Yeast RSP5 and its human homolog hRPF1 potentiate hormone-dependent activation of transcription by human progesterone and glucocorticoid receptors. Mol. Cell. Biol. 16: 2594-2605.

Ito, M., C.X. Yuan, S. Malik, W. Gu, J.D. Fondell, S. Yamamura, Z.Y. Fu, X. Zhang, J. Qin, and R.G. Roeder. 1999. Identity between TRAP and SMCC complexes indicates novel pathways for the function of nuclear receptors and diverse mam- malian activators. Mol. Cell 3: 361-370.

Ito, T., M. Bulger, M.J. Pazin, R. Kobayashi, and J.T. Kadonaga. 1997. ACF, an ISWI-containing and ATP-utilizing chromatin assembly and remodeling factor. Cell 90: 145-155.

Jackson, T.A., J.K. Richer, D.L. Bain, G.S. Takimoto, L. Tung, and K.B. Horwitz. 1997. The partial agonist activity of antagonist-occupied steroid receptors is controlled by a novel hinge domain-binding coactivator L7/SPA and the corepressors N-CoR or SMRT. Mol. Endocrinol. 11: 693-705.

Jonat, C., H.J. Rahmsdorf, K.K. Park, A.C. Cato, S. Gebel, H. Ponta, and P. Herrlich. 1990. Antitumor promotion and antiinflammation: down-modulation of AP-1 (Fos/Jun) activity by glucocorticoid hormone. Cell 62: 1189-1204.

Kadosh, D. and K. Struhl. 1997. Repression by Ume6 involves recruitment of a complex containing Sin 3 corepressor and Rpd3 histone deacetylase to target promoters. Cell 89: 365371.

Kamei, Y., L. Xu, T. Heinzel, J. Torchia, R. Kurokawa, B. Gloss, S.C. Lin, R.A. Heyman, D.W. Rose, C.K. Glass, and M.G. Rosenfeld. 1996. A CBP integrator complex mediates transcriptional activation and AP-1 inhibition by nuclear receptors. Cell 85: 403-414.

Kang, H.Y., S. Yeh, N. Fujimoto, and C. Chang. 1999. Cloning and characterization of human prostate coactivator ARA54, a novel protein that associates with the androgen receptor. J. Biol. Chem. 274: 8570-8576.

Kao, H.Y., P. Ordentlich, N. Koyano-Nakagawa, Z. Tang, M. Downes, C.R. Kintner, R.M. Evans, and T. Kadesch. 1998. A histone deacetylase corepressor complex regulates the Notch signal transduction pathway. Genes \& Dev. 12: 22692277.

Kao, H.-Y., M. Downes, P. Ordentlich, and R.M. Evans. 2000. Isolation of a novel histone deacetylase reveals that class I and class II deacetylases promote SMRT-mediated repression. Genes \& Dev. 14: 55-66.

Kawasaki, H., R. Eckner, T.P. Yao, K. Taira, R. Chiu, D.M. Livingston, and K.K. Yokoyama. 1998. Distinct roles of the co-activators p300 and CBP in retinoic-acid-induced F9-cell differentiation. Nature 393: 284-289.

Khavari, P.A., C.L. Peterson, J.W. Tamkun, D.B. Mendel, and G.R. Crabtree. 1993. BRG1 contains a conserved domain of the SWI2/SNF2 family necessary for normal mitotic growth and transcription. Nature 366: 170-174.

Kingston, R.E. and G.J. Narlikar. 1999. ATP-dependent remodeling and acetylation as regulators of chromatin fluidity. Genes \& Dev. 13: 2339-2352.

Kliewer, S.A., K. Umesono, D.J. Noonan, R.A. Heyman, and R.M. Evans. 1992. Convergence of 9-cis retinoic acid and peroxisome proliferator signalling pathways through heterodimer formation of their receptors. Nature 358: 771774.

Korzus, E., J. Torchia, D.W. Rose, L. Xu, R. Kurokawa, E.M. McInerney, T.M. Mullen, C.K. Glass, and M.G. Rosenfeld. 1998. Transcription factor-specific requirements for coactivators and their acetyltransferase functions. Science 279: 703-707.

Kraus, W.L. and J.T. Kadonaga. 1998. p300 and estrogen receptor cooperatively activate transcription via differential enhancement of initiation and reinitiation. Genes \& Dev. 12: 331342.

Krebs, J.E., M.H. Kuo, C.D. Allis, and C.L. Peterson. 1999. Cell cycle-regulated histone acetylation required for expression of the yeast HO gene. Genes \& Dev. 13: 1412-1421.

Kuo, M.H., J.E. Brownell, R.E. Sobel, T.A. Ranalli, R.G. Cook, D.G. Edmondson, S.Y. Roth, and C.D. Allis. 1996. Transcription-linked acetylation by Gen5p of histones H3 and H4 at 
specific lysines. Nature 383: 269-272.

Kurokawa, R., J. DiRenzo, M. Boehm, J. Sugarman, B. Gloss, M.G. Rosenfeld, R.A. Heyman, and C.K. Glass. 1994. Regulation of retinoid signalling by receptor polarity and allosteric control of ligand binding. Nature 371: 528-531.

Kurokawa, R., M. Soderstrom, A. Horlein, S. Halachmi, M. Brown, M.G. Rosenfeld, and C.K. Glass. 1995. Polarity-specific activities of retinoic acid receptors determined by a co-repressor. Nature 377: 451-454.

Kurokawa, R., D. Kalafus, M.H. Ogliastro, C. Kioussi, L. Xu, J. Torchia, M.G. Rosenfeld, and C.K. Glass. 1998. Differential use of CREB binding protein-coactivator complexes. Science 279: 700-703.

Laherty, C.D., W.M. Yang, J.M. Sun, J.R. Davie, E. Seto, and R.N. Eisenman. 1997. Histone deacetylases associated with the $\mathrm{mSin} 3$ corepressor mediate mad transcriptional repression. Cell 89: 349-356.

Laherty, C.D., A.N. Billin, R.M. Lavinsky, G.S. Yochum, A.C. Bush, J.M. Sun, T.M. Mullen, J.R. Davie, D.W. Rose, C.K. Glass, M.G. Rosenfeld, D.E. Ayer, and R.N. Eisenman. 1998. SAP30, a component of the mSin3 corepressor complex involved in N-CoR- mediated repression by specific transcription factors. Mol. Cell. 2: 33-42.

Lanz, R.B. and S. Rusconi. 1994. A conserved carboxy-terminal subdomain is important for ligand interpretation and transactivation by nuclear receptors. Endocrinology 135: 2183 2195.

Lanz, R.B., N.J. McKenna, S.A. Onate, U. Albrecht, J. Wong, S.Y. Tsai, M.J. Tsai, and B.W. O'Malley. 1999. A steroid receptor coactivator, SRA, functions as an RNA and is present in an SRC-1 complex. Cell 97: 17-27.

Laurent, B.C., I. Treich, and M. Carlson. 1993. The yeast SNF2/ SWI2 protein has DNA-stimulated ATPase activity required for transcriptional activation. Genes \& Dev. 7: 583-591.

Lavinsky, R.M., K. Jepsen, T. Heinzel, J. Torchia, T.M. Mullen, R. Schiff, A.L. Del-Rio, M. Ricote, S. Ngo, J. Gemsch, S.G. Hilsenbeck, C.K. Osborne, C.K. Glass, M.G. Rosenfeld, and D.W. Rose. 1998. Diverse signaling pathways modulate nuclear receptor recruitment of N-CoR and SMRT complexes. Proc. Nat1. Acad. Sci. 95: 2920-2925.

Le Douarin, B., C. Zechel, J.M. Garnier, Y. Lutz, L. Tora, P. Pierrat, D. Heery, H. Gronemeyer, P. Chambon, and R. Losson. 1995. The N-terminal part of TIF1, a putative mediator of the ligand-dependent activation function (AF-2) of nuclear receptors, is fused to B-raf in the oncogenic protein $\mathrm{T} 18$. EMBO I. 14: 2020-2033.

Le Douarin, B., A.L. Nielsen, J.M. Garnier, H. Ichinose, F. Jeanmougin, R. Losson, and P. Chambon. 1996. A possible involvement of TIF1 $\alpha$ and TIF1 $\beta$ in the epigenetic control of transcription by nuclear receptors. EMBO J. 15: 67016715.

Lee, J.W., H.S. Choi, J. Gyuris, R. Brent, and D.D. Moore. 1995a. Two classes of proteins dependent on either the presence or absence of thyroid hormone for interaction with the thyroid hormone receptor. Mol. Endocrinol. 9: 243-254.

Lee, J.W., F. Ryan, J.C. Swaffield, S.A. Johnston, and D.D. Moore. 1995b. Interaction of thyroid-hormone receptor with a conserved transcriptional mediator. Nature 374: 91-94.

Lee, T.I. and R.A. Young. 1998. Regulation of gene expression by TBP-associated proteins. Genes \& Dev. 12: 1398-1408.

Lee, Y., B. Nadal-Ginard, V. Mahdavi, and S. Izumo. 1997. Myocyte-specific enhancer factor 2 and thyroid hormone receptor associate and synergistically activate the alpha-cardiac myosin heavy- chain gene. Mol. Cell. Biol. 17: 2745-2755.

Li, H., P.J. Gomes, and J.D. Chen. 1997a. RAC3, a steroid/ nuclear receptor-associated coactivator that is related to
SRC-1 and TIF2. Proc. Nat1. Acad. Sci. 94: 8479-8484.

Li, H., C. Leo, D.J. Schroen, and J.D. Chen. 1997b. Characterization of receptor interaction and transcriptional repression by the corepressor SMRT. Mol. Endocrinol. 11: 2025-2037.

Li, Q., A. Imhof, T.N. Collingwood, F.D. Urnov, and A.P. Wolffe. 1999. p300 stimulates transcription instigated by ligand-bound thyroid hormone receptor at a step subsequent to chromatin disruption. EMBO J. 18: 5634-5652.

Logie, C., C. Tse, J.C. Hansen, and C.L. Peterson. 1999. The core histone $\mathrm{N}$-terminal domains are required for multiple rounds of catalytic chromatin remodeling by the SWI/SNF and RSC complexes. Biochemistry 38: 2514-2522.

Mangelsdorf, D.J. and R.M. Evans. 1995. The RXR heterodimers and orphan receptors. Cell 83: 841-850.

Mannervik, M., Y. Nibu, H. Zhang, and M. Levine. 1999. Transcriptional coregulators in development. Science 284: 606609.

Martinez-Balbas, M.A., A.J. Bannister, K. Martin, P. Haus-Seuffert, M. Meisterernst, and T. Kouzarides. 1998. The acetyltransferase activity of CBP stimulates transcription. EMBO J. 17: 2886-2893.

McInerney, E.M., D.W. Rose, S.E. Flynn, S. Westin, T.M. Mullen, A. Krones, J. Inostroza, J. Torchia, R.T. Nolte, N. Assa-Munt, M.V. Milburn, C.K. Glass, and M.G. Rosenfeld. 1998. Determinants of coactivator LXXLL motif specificity in nuclear receptor transcriptional activation. Genes \& Dev. 12: 3357-3368.

McKenna, N.J., R.B. Lanz, and B.W. O'Malley. 1999. Nuclear receptor coregulators: cellular and molecular biology. Endocr. Rev. 20: 321-344.

Miller, R.W. and J.H. Rubinstein. 1995. Tumors in RubinsteinTaybi syndrome. Am. J. Med. Genet. 56: 112-115.

Miyamoto, H., S. Yeh, G. Wilding, and C. Chang. 1998. Promotion of agonist activity of antiandrogens by the androgen receptor coactivator, ARA70, in human prostate cancer DU145 cells. Proc. Nat1. Acad. Sci. 95: 7379-7384.

Mizzen, C.A., X.J. Yang, T. Kokubo, J.E. Brownell, A.J. Bannister, T. Owen-Hughes, J. Workman, L. Wang, S.L. Berger, T. Kouzarides, Y. Nakatani, and C.D. Allis. 1996. The TAF(II)250 subunit of TFIID has histone acetyltransferase activity. Cell 87: 1261-1270.

Moilanen, A.M., H. Poukka, U. Karvonen, M. Hakli, O.A. Janne, and J.J. Palvimo. 1998. Identification of a novel RING finger protein as a coregulator in steroid receptor-mediated gene transcription. Mol. Cell. Biol. 18: 5128-5139.

Moosmann, P., O. Georgiev, B. Le Douarin, J.P. Bourquin, and W. Schaffner. 1996. Transcriptional repression by RING finger protein TIF1 beta that interacts with the KRAB repressor domain of KOX1. Nucleic Acids Res. 24: 4859-4867.

Moras, D. and H. Gronemeyer. 1998. The nuclear receptor ligand-binding domain: structure and function. Curr. Opin. Cell. Biol. 10: 384-391.

Muchardt, C. and M. Yaniv. 1993. A human homologue of Saccharomyces cerevisiae SNF2/SWI2 and Drosophila brm genes potentiates transcriptional activation by the glucocorticoid receptor. EMBO J. 12: 4279-4290.

Munshi, N., M. Merika, J. Yie, K. Senger, G. Chen, and D. Thanos. 1998. Acetylation of HMG I(Y) by CBP turns off IFN $\beta$ expression by disrupting the enhanceosome. Mol. Cell 2: 457-467.

Naar, A.M., P.A. Beaurang, S. Zhou, S. Abraham, W. Solomon, and R. Tjian. 1999. Composite co-activator ARC mediates chromatin-directed transcriptional activation. Nature 398: 828-832.

Nagy, L., H.Y. Kao, D. Chakravarti, R.J. Lin, C.A. Hassig, D.E. Ayer, S.L. Schreiber, and R.M. Evans. 1997. Nuclear re- 
ceptor repression mediated by a complex containing SMRT, mSin3A, and histone deacetylase. Cell 89:373380.

Nagy, L., H.Y. Kao, J.D. Love, C. Li, E. Banayo, J.T. Gooch, V. Krishna, K. Chatterjee, R.M. Evans, and J.W.R. Schwabe. 1999. Mechanism of corepressor binding and release from nuclear hormone receptors. Genes \& Dev. 13: 3209-3216.

Nakajima, T., A. Fukamizu, J. Takahashi, F.H. Gage, T. Fisher, J. Blenis, and M.R. Montminy. 1996. The signal-dependent coactivator CBP is a nuclear target for pp90RSK. Cell 86: 465-474.

Nakajima, T., C. Uchida, S.F. Anderson, C.G. Lee, J. Hurwitz, J.D. Parvin, and M. Montminy. 1997. RNA helicase A mediates association of CBP with RNA polymerase II. Cell 90: $1107-1112$.

Nasmyth, K., D. Stillman, and D. Kipling. 1987. Both positive and negative regulators of $\mathrm{HO}$ transcription are required for mother-cell-specific mating-type switching in yeast. Cell 48: $579-587$.

Nawaz, Z., D.M. Lonard, C.L. Smith, E. Lev-Lehman, S.Y. Tsai, M.J. Tsai, and B.W. O'Malley. 1999. The Angelman syndrome-associated protein, E6-AP, is a coactivator for the nuclear hormone receptor superfamily. Mol. Cell. Biol. 19: 1182-1189.

Nibu, Y., H. Zhang, E. Bajor, S. Barolo, S. Small, and M. Levine. 1998a. dCtBP mediates transcriptional repression by Knirps, Kruppel and Snail in the Drosophila embryo. EMBO $I$. 17: 7009-7020.

Nibu, Y., H. Zhang, and M. Levine. 1998b. Interaction of shortrange repressors with Drosophila CtBP in the embryo. Science 280: 101-104.

Nolte, R.T., G.B. Wisely, S. Westin, J.E. Cobb, M.H. Lambert, R. Kurokawa, M.G. Rosenfeld, T.M. Willson, C.K. Glass, and M.V. Milburn. 1998. Ligand binding and co-activator assembly of the peroxisome proliferator- activated receptorgamma. Nature 395: 137-143.

Ogryzko, V.V., R.L. Schiltz, V. Russanova, B.H. Howard, and Y. Nakatani. 1996. The transcriptional coactivators p300 and CBP are histone acetyltransferases. Cell 87:953959.

Ogryzko, V.V., T. Kotani, X. Zhang, R.L. Schlitz, T. Howard, X.J. Yang, B.H. Howard, J. Qin, and Y. Nakatani. 1998. Histonelike TAFs within the PCAF histone acetylase complex. Cell 94: 35-44.

Oike, Y., A. Hata, T. Mamiya, T. Kaname, Y. Noda, M. Suzuki, H. Yasue, T. Nabeshima, K. Araki, and K. Yamamura. 1999a. Truncated CBP protein leads to classical RubinsteinTaybi syndrome phenotypes in mice: implications for a dominant-negative mechanism. Hum. Mol. Genet. 8: 387396.

Oike, Y., N. Takakura, A. Hata, T. Kaname, M. Akizuki, Y. Yamaguchi, H. Yasue, K. Araki, K. Yamamura, and T. Suda. 1999b. Mice homozygous for a truncated form of CREBbinding protein exhibit defects in hematopoiesis and vasculo-angiogenesis. Blood 93: 2771-2779.

Onate, S.A., S.Y. Tsai, M.J. Tsai, and B.W. O'Malley. 1995. Sequence and characterization of a coactivator for the steroid hormone receptor superfamily. Science 270: 1354-1357.

Ordentlich, P., M. Downes, W. Xie, A. Genin, N.B. Spinner, and R.M. Evans. 1999. Unique forms of human and mouse nuclear receptor corepressor SMRT. Proc. Natl. Acad. Sci. 96: $2639-2644$.

Ostlund Farrants, A.K., P. Blomquist, H. Kwon, and O. Wrange. 1997. Glucocorticoid receptor-glucocorticoid response element binding stimulates nucleosome disruption by the SWI/ SNF complex. Mol. Cell. Biol. 17: 895-905.
Owen-Hughes, T., R.T. Utley, J. Cote, C.L. Peterson, and J.L. Workman. 1996. Persistent site-specific remodeling of a nucleosome array by transient action of the SWI/SNF complex. Science 273: 513-516.

Park, E.J., D.J. Schroen, M. Yang, H. Li, L. Li, and J.D. Chen. 1999. SMRTe, a silencing mediator for retinoid and thyroid hormone receptors- extended isoform that is more related to the nuclear receptor corepressor. Proc. Natl. Acad. Sci. 96: 3519-3524.

Pazin, M.J. and J.T. Kadonaga. 1997. SWI2/SNF2 and related proteins: ATP-driven motors that disrupt protein- DNA interactions? Cell 88: 737-740.

Perissi, V., J.S. Dasen, R. Kurokawa, Z. Wang, E. Korzus, D.W. Rose, C.K. Glass, and M.G. Rosenfeld. 1999a. Factor-specific modulation of CREB-binding protein acetyltransferase activity. Proc. Nat1. Acad. Sci. 96: 3652-3657.

Perissi, V., L.M. Staszewski, E.M. McInerney, R Kurokawa, A. Krones, D.W. Rose, M.H. Lambert, M.V. Milturn, C.K. Glass, and M.G. Rosenfeld. 1999b. Molecular determinants of nuclear receptor-corepressor interaction. Genes \& Dev. 13: $3198-3308$.

Peterson, C.L. 1996. Multiple SWItches to turn on chromatin? Curr. Opin. Genet. Dev. 6: 171-175.

Petrij, F., R.H. Giles, H.G. Dauwerse, J.J. Saris, R.C. Hennekam, M. Masuno, N. Tommerup, G.J. van Ommen, R.H. Goodman, D.J. Peters, and et al. 1995. Rubinstein-Taybi syndrome caused by mutations in the transcriptional co- activator CBP. Nature 376: 348-351.

Pollard, K.J. and C.L. Peterson. 1998. Chromatin remodeling: a marriage between two families? BioEssays 20: 771-780.

Poortinga, G., M. Watanabe, and S.M. Parkhurst. 1998. Drosophila CtBP: a Hairy-interacting protein required for embryonic segmentation and hairy-mediated transcriptional repression. EMBO J. 17: 2067-2078.

Puigserver, P., Z. Wu, C.W. Park, R. Graves, M. Wright, and B.M. Spiegelman. 1998. A cold-inducible coactivator of nuclear receptors linked to adaptive thermogenesis. Cell 92: 829-839.

Puri, P.L., V. Sartorelli, X.J. Yang, Y. Hamamori, V.V. Ogryzko, B.H. Howard, L. Kedes, J.Y. Wang, A. Graessmann, Y. Nakatani, and M. Levrero. 1997. Differential roles of p300 and PCAF acetyltransferases in muscle differentiation. Mol. Cell 1: 35-45.

Qi, C., Y. Zhu, J. Pan, A.V. Yeldandi, M.S. Rao, N. Maeda, V. Subbarao, S. Pulikuri, T. Hashimoto, and J.K. Reddy. 1999. Mouse steroid receptor coactivator- 1 is not essential for peroxisome proliferator-activated receptor alpha-regulated gene expression. Proc. Natl. Acad. Sci. 96: 1585-1590.

Rachez, C., Z. Suldan, J. Ward, C.P. Chang, D. Burakov, H. Erdjument-Bromage, P. Tempst, and L.P. Freedman. 1998. A novel protein complex that interacts with the vitamin D3 receptor in a ligand-dependent manner and enhances VDR transactivation in a cell- free system. Genes \& Dev. 12: $1787-1800$.

Rachez, C., B.D. Lemon, Z. Suldan, V. Bromleigh, M. Gamble, A.M. Naar, H. Erdjument-Bromage, P. Tempst, and L.P. Freedman. 1999. Ligand-dependent transcription activation by nuclear receptors requires the DRIP complex. Nature 398: 824-828.

Reichardt, H.M., K.H. Kaestner, J. Tuckermann, O. Kretz, O. Wessely, R. Bock, P. Gass, W. Schmid, P. Herrlich, P. Angel, and G. Schutz. 1998. DNA binding of the glucocorticoid receptor is not essential for survival. Cell 93: 531-541.

Renaud, J.P., N. Rochel, M. Ruff, V. Vivat, P. Chambon, H. Gronemeyer, and D. Moras. 1995. Crystal structure of the RAR- $\gamma$ ligand-binding domain bound to all-trans retinoic 
acid. Nature 378: 681-689.

Romine, L.E., J.R. Wood, L.A. Lamia, P. Prendergast, D.P. Edwards, and A.M. Nardulli. 1998. The high mobility group protein 1 enhances binding of the estrogen receptor DNA binding domain to the estrogen response element. Mol. Endocrinol. 12: 664-674.

Rubin, D.M., O. Coux, I. Wefes, C. Hengartner, R.A. Young, A.L. Goldberg, and D. Finley. 1996. Identification of the gal4 suppressor Sug1 as a subunit of the yeast 26S proteasome. Nature 379: 655-657.

Ryu, S., S. Zhou, A.G. Ladurner, and R. Tjian. 1999. The transcriptional cofactor complex CRSP is required for activity of the enhancer-binding protein Sp1. Nature 397: 446450.

Saatcioglu, F., T. Deng, and M. Karin. 1993. A novel cis element mediating ligand-independent activation by c-ErbA: implications for hormonal regulation. Cell 75: 1095-1105.

Sande, S. and M.L. Privalsky. 1996. Identification of TRACs (T3 receptor-associating cofactors), a family of cofactors that associate with, and modulate the activity of, nuclear hormone receptors. Mol. Endocrinol. 10: 813-825.

Sasaki, S., L.A. Lesoon-Wood, A. Dey, T. Kuwata, B.D. Weintraub, G. Humphrey, W.M. Yang, E. Seto, P.M. Yen, B.H. Howard, and K. Ozato. 1999. Ligand-induced recruitment of a histone deacetylase in the negative- feedback regulation of the thyrotropin $\beta$ gene. EMBO J. 18: 5389-5398.

Sauer, F., J.D. Fondell, Y. Ohkuma, R.G. Roeder, and H. Jackle. 1995. Control of transcription by Kruppel through interactions with TFIIB and TFIIE $\beta$. Nature 375: 162-164.

Sauer, F., R. Rivera-Pomar, M. Hoch, and H. Jackle. 1996. Gene regulation in the Drosophila embryo. Philos. Trans. R. Soc. Lond. B. Biol. Sci. 351: 579-587.

Schaeper, U., J.M. Boyd, S. Verma, E. Uhlmann, T. Subramanian, and G. Chinnadurai. 1995. Molecular cloning and characterization of a cellular phosphoprotein that interacts with a conserved C-terminal domain of adenovirus E1A involved in negative modulation of oncogenic transformation. Proc. Nat1. Acad. Sci. 92: 10467-10471.

Schreiber-Agus, N., L. Chin, K. Chen, R. Torres, G. Rao, P. Guida, A.I. Skoultchi, and R.A. DePinho. 1995. An amino-terminal domain of Mxil mediates anti-Myc oncogenic activity and interacts with a homolog of the yeast transcriptional repressor SIN3. Cell 80: 777786.

Schule, R., P. Rangarajan, N. Yang, S. Kliewer, L.J. Ransone, J. Bolado, I.M. Verma, and R.M. Evans. 1991. Retinoic acid is a negative regulator of AP-1-responsive genes. Proc. Natl. Acad. Sci. 88: 6092-6096.

Seol, W., M.J. Mahon, Y.K. Lee, and D.D. Moore. 1996. Two receptor interacting domains in the nuclear hormone receptor corepressor RIP13/N-CoR. Mol. Endocrinol. 10: 16461655.

Shao, D. and M.A. Lazar. 1999. Modulating nuclear receptor function: may the phos be with you. I. Clin. Invest. 103: $1617-1618$.

Shiau, A.K., D. Barstad, P.M. Loria, L. Cheng, P.J. Kushner, D.A. Agard, and G.L. Greene. 1998. The structural basis of estrogen receptor/coactivator recognition and the antagonism of this interaction by tamoxifen. Cell 95: 927-937.

Shibata, H., Z. Nawaz, S.Y. Tsai, B.W. O'Malley, and M.J. Tsai. 1997. Gene silencing by chicken ovalbumin upstream promoter-transcription factor I (COUP-TFI) is mediated by transcriptional corepressors, nuclear receptor-corepressor $(\mathrm{N}$ $\mathrm{CoR}$ ) and silencing mediator for retinoic acid receptor and thyroid hormone receptor (SMRT). Mol. Endocrinol. 11: 714-724.
Siegfried, E. and N. Perrimon. 1994. Drosophila wingless: a paradigm for the function and mechanism of Wnt signaling. BioEssays 16: 395-404.

Sil, A. and I. Herskowitz. 1996. Identification of asymmetrically localized determinant, Ash1p, required for lineagespecific transcription of the yeast HO gene. Cell 84: 711722.

Sluder, A.E., S.W. Mathews, D. Hough, V.P. Yin, and C.V. Maina. 1999. The nuclear receptor superfamily has undergone extensive proliferation and diversification in nematodes. Genome Res 9: 103-120.

Smith, C.L., Z. Nawaz, and B.W. O'Malley. 1997. Coactivator and corepressor regulation of the agonist/antagonist activity of the mixed antiestrogen, 4-hydroxytamoxifen. Mol. Endocrinol. 11: 657-666.

Soderstrom, M., A. Vo, T. Heinzel, R.M. Lavinsky, W.M. Yang, E. Seto, D.A. Peterson, M.G. Rosenfeld, and C.K. Glass. 1997. Differential effects of nuclear receptor corepressor (N$\mathrm{CoR}$ ) expression levels on retinoic acid receptor-mediated repression support the existence of dynamically regulated corepressor complexes. Mol. Endocrinol. 11: 682-692.

Spencer, T.E., G. Jenster, M.M. Burcin, C.D. Allis, J. Zhou, C.A. Mizzen, N.J. McKenna, S.A. Onate, S.Y. Tsai, M.J. Tsai, and B.W. O'Malley. 1997. Steroid receptor coactivator-1 is a histone acetyltransferase. Nature 389: 194-198.

Struhl, K. 1998. Histone acetylation and transcriptional regulatory mechanisms. Genes \& Dev. 12: 599-606.

Suen, C.S., T.J. Berrodin, R. Mastroeni, B.J. Cheskis, C.R. Lyttle, and D.E. Frail. 1998. A transcriptional coactivator, steroid receptor coactivator-3, selectively augments steroid receptor transcriptional activity. J. Biol. Chem. 273: 27645-27653.

Sun, X., Y. Zhang, H. Cho, P. Rickert, E. Lees, W. Lane, and D. Reinberg. 1998. NAT, a human complex containing Srb polypeptides that functions as a negative regulator of activated transcription. Mol. Cell 2: 213-222.

Tagami, T., L.D. Madison, T. Nagaya, and J.L. Jameson. 1997. Nuclear receptor corepressors activate rather than suppress basal transcription of genes that are negatively regulated by thyroid hormone. Mol. Cell. Biol. 17: 2642-2648.

Takeshita, A., G.R. Cardona, N. Koibuchi, C.S. Suen, and W.W. Chin. 1997. TRAM-1, A novel 160-kDa thyroid hormone receptor activator molecule, exhibits distinct properties from steroid receptor coactivator-1. I. Biol. Chem. 272: 27629-27634.

Tamkun, J.W., R. Deuring, M.P. Scott, M. Kissinger, A.M. Pattatucci, T.C. Kaufman, and J.A. Kennison. 1992. brahma: a regulator of Drosophila homeotic genes structurally related to the yeast transcriptional activator SNF2/SWI2. Cell 68: $561-572$.

Tanaka, Y., I. Naruse, T. Maekawa, H. Masuya, T. Shiroishi, and S. Ishii. 1997. Abnormal skeletal patterning in embryos lacking a single Cbp allele: a partial similarity with RubinsteinTaybi syndrome. Proc. Natl. Acad. Sci. 94: 10215-10220.

Taunton, J., C.A. Hassig, and S.L. Schreiber. 1996. A mammalian histone deacetylase related to the yeast transcriptional regulator Rpd3p. Science 272: 408-411.

Torchia, J., D.W. Rose, J. Inostroza, Y. Kamei, S. Westin, C.K. Glass, and M.G. Rosenfeld. 1997. The transcriptional coactivator $\mathrm{p} / \mathrm{CIP}$ binds CBP and mediates nuclear-receptor function. Nature 387: 677-684.

Treitel, M.A., S. Kuchin, and M. Carlson. 1998. Snf1 protein kinase regulates phosphorylation of the Mig1 repressor in Saccharomyces cerevisiae. Mol. Cell. Biol. 18: 6273-6280.

Tremblay, A., G.B. Tremblay, F. Labrie, and V. Giguere. 1999. Ligand-independent recruitment of SRC-1 to estrogen receptor beta through phosphorylation of activation function AF- 
1. Mol. Cell 3: 513-519.

Treuter, E., L. Johansson, J.S. Thomsen, A. Warnmark, J. Leers, M. Pelto-Huikko, M. Sjoberg, A.P. Wright, G. Spyrou, and J.A. Gustafsson. 1999. Competition between thyroid hormone receptor-associated protein (TRAP) 220 and transcriptional intermediary factor (TIF) 2 for binding to nuclear receptors. Implications for the recruitment of TRAP and p160 coactivator complexes. J. Biol. Chem. 274: 66676677.

Trievel, R.C., J.R. Rojas, D.E. Sterner, R.N. Venkataramani, L. Wang, J. Zhou, C.D. Allis, S.L. Berger, and R. Marmorstein. 1999. Crystal structure and mechanism of histone acetylation of the yeast GCN5 transcriptional coactivator. Proc. Nat1. Acad. Sci. 96: 8931-8936.

Tsukiyama, T. and C. Wu. 1995. Purification and properties of an ATP-dependent nucleosome remodeling factor. Cell 83: 1011-1020.

Varga-Weisz, P.D., M. Wilm, E. Bonte, K. Dumas, M. Mann, and P.B. Becker. 1997. Chromatin-remodelling factor CHRAC contains the ATPases ISWI and topoisomerase II. Nature 388: 598-602.

Vegeto, E., G.F. Allan, W.T. Schrader, M.J. Tsai, D.P. McDonnell, and B.W. O'Malley. 1992. The mechanism of RU486 antagonism is dependent on the conformation of the carboxy-terminal tail of the human progesterone receptor. Cell 69: 703-713.

Verrier, C.S., N. Roodi, C.J. Yee, L.R. Bailey, R.A. Jensen, M. Bustin, and F.F. Parl. 1997. High-mobility group (HMG) protein HMG-1 and TATA-binding protein-associated factor TAF(II)30 affect estrogen receptor-mediated transcriptional activation. Mol. Endocrinol. 11: 1009-1019.

Vidal, M., R. Strich, R.E. Esposito, and R.F. Gaber. 1991. RPD1 (SIN3/UME4) is required for maximal activation and repression of diverse yeast genes. Mol. Cell. Biol. 11: 63066316.

Voegel, J.J., M.J. Heine, M. Tini, V. Vivat, P. Chambon, and H. Gronemeyer. 1998. The coactivator TIF2 contains three nuclear receptor-binding motifs and mediates transactivation through CBP binding-dependent and -independent pathways. EMBO J. 17: 507-519.

vom Baur, E., M. Harbers, S.J. Um, A. Benecke, P. Chambon, and R. Losson. 1998. The yeast Ada complex mediates the ligand-dependent activation function AF-2 of retinoid X and estrogen receptors. Genes \& Dev. 12: 1278-1289.

Wade, P.A. and A.P. Wolffe. 1999. Transcriptional regulation: SWItching circuitry. Curr. Biol. 9: R221-224.

Wade, P.A., P.L. Jones, D. Vermaak, and A.P. Wolffe. 1998. A multiple subunit Mi-2 histone deacetylase from Xenopus laevis cofractionates with an associated Snf2 superfamily ATPase. Curr. Biol. 8: 843-846.

Wagner, B.L., J.D. Norris, T.A. Knotts, N.L. Weigel, and D.P. McDonnell. 1998. The nuclear corepressors NCoR and SMRT are key regulators of both ligand- and 8-bromo-cyclic AMP-dependent transcriptional activity of the human progesterone receptor. Mol. Cell. Biol. 18: 1369-1378.

Wagner, R.L., J.W. Apriletti, M.E. McGrath, B.L. West, J.D. Baxter, and R.J. Fletterick. 1995. A structural role for hormone in the thyroid hormone receptor. Nature 378: 690-697.

Waltzer, L. and M. Bienz. 1998. Drosophila CBP represses the transcription factor TCF to antagonize Wingless signalling. Nature 395: 521-525.

Westin, S., R. Kurokawa, R.T. Nolte, G.B. Wisely, E.M. McInerney, D.W. Rose, M.V. Milburn, M.G. Rosenfeld, and C.K. Glass. 1998. Interactions controlling the assembly of nuclear-receptor heterodimers and co-activators. Nature 395: 199-202.
Woloshin, P., K. Song, C. Degnin, A.M. Killary, D.J. Goldhamer, D. Sassoon, and M.J. Thayer. 1995. MSX1 inhibits myoD expression in fibroblast $\mathrm{x}$ 10T1/2 cell hybrids. Cell 82: 611620.

Workman, J.L. and R.E. Kingston. 1998. Alteration of nucleosome structure as a mechanism of transcriptional regulation. Annu. Rev. Biochem. 67: 545-579.

$\mathrm{Wu}, \mathrm{C}$. 1997. Chromatin remodeling and the control of gene expression. J. Biol. Chem. 272: 28171-28174.

Xu, J., Z. Nawaz, S.Y. Tsai, M.J. Tsai, and B.W. O'Malley. 1996. The extreme C-terminus of progesterone receptor contains a transcriptional repressor domain that functions through a putative corepressor. Proc. Natl. Acad. Sci. 93: 1219512199.

Xu, J., Y. Qiu, F.J. DeMayo, S.Y. Tsai, M.J. Tsai, and B.W. O'Malley. 1998. Partial hormone resistance in mice with disruption of the steroid receptor coactivator-1 (SRC-1) gene. Science 279: 1922-1925.

Yang, X.J., V.V. Ogryzko, J. Nishikawa, B.H. Howard, and Y. Nakatani. 1996. A p300/CBP-associated factor that competes with the adenoviral oncoprotein E1A. Nature 382: 319-324.

Yang-Yen, H.F., J.C. Chambard, Y.L. Sun, T. Smeal, T.J. Schmidt, J. Drouin, and M. Karin. 1990. Transcriptional interference between c-Jun and the glucocorticoid receptor: mutual inhibition of DNA binding due to direct proteinprotein interaction. Cell 62: 1205-1215.

Yao, T.P., G. Ku, N. Zhou, R. Scully, and D.M. Livingston. 1996. The nuclear hormone receptor coactivator SRC-1 is a specific target of p300. Proc. Natl. Acad. Sci. 93: 10626-10631.

Yao, T.P., S.P. Oh, M. Fuchs, N.D. Zhou, L.E. Ch'ng, D. Newsome, R.T. Bronson, E. Li, D.M. Livingston, and R. Eckner. 1998. Gene dosage-dependent embryonic development and proliferation defects in mice lacking the transcriptional integrator p300. Cell 93: 361-372.

Yeh, S. and C. Chang. 1996. Cloning and characterization of a specific coactivator, ARA70, for the androgen receptor in human prostate cells. Proc. Nat1. Acad. Sci. 93: 5517-5521.

Yoh, S.M., V.K. Chatterjee, and M.L. Privalsky. 1997. Thyroid hormone resistance syndrome manifests as an aberrant interaction between mutant $\mathrm{T} 3$ receptors and transcriptional corepressors. Mol. Endocrinol. 11: 470-480.

Yoshinaga, S.K., C.L. Peterson, I. Herskowitz, and K.R. Yamamoto. 1992. Roles of SWI1, SWI2, and SWI3 proteins for transcriptional enhancement by steroid receptors. Science 258: $1598-1604$.

Yuan, C.X., M. Ito, J.D. Fondell, Z.Y. Fu, and R.G. Roeder. 1998. The TRAP220 component of a thyroid hormone receptorassociated protein (TRAP) coactivator complex interacts directly with nuclear receptors in a ligand-dependent fashion. Proc. Nat1. Acad. Sci. 95: 7939-7944.

Zamir, I., H.P. Harding, G.B. Atkins, A. Horlein, C.K. Glass, M.G. Rosenfeld, and M.A. Lazar. 1996. A nuclear hormone receptor corepressor mediates transcriptional silencing by receptors with distinct repression domains. Mol. Cell. Biol. 16: 5458-5465.

Zamir, I., J. Dawson, R.M. Lavinsky, C.K. Glass, M.G. Rosenfeld, and M.A. Lazar. 1997. Cloning and characterization of a corepressor and potential component of the nuclear hormone receptor repression complex. Proc. Natl. Acad. Sci. 94: 14400-14405.

Zhang, J., M.G. Guenther, R.W. Carthew, and M.A. Lazar. 1998c. Proteasonal regulation of nuclear receptor corepressor-memdiated repression. Genes Dev 12: 1775-1778.

Zhang, X., M. Jeyakumar, S. Petukhov, and M.K. Bagchi. 1998a. A nuclear receptor corepressor modulates transcriptional ac- 
tivity of antagonist-occupied steroid hormone receptor. Mol. Endocrinol. 12: 513-524.

Zhang, Y., R. Iratni, H. Erdjument-Bromage, P. Tempst and D Reinberg. 1997. Histone deacetylases and SAP18, a novel peptide, are components of a human Sin3 complex. Cell 89: 357-364.

Zhang, Y., Z.W. Sun, R. Iratni, H. Erdjument-Bromage, P. Tempst, M. Hampsey, and D. Reinberg. 1998b. SAP30, a novel protein conserved between human and yeast, is a component of a histone deacetylase complex. Mol. Cell 1: 10211031.

Zhu, Y., C. Qi, S. Jain, M.S. Rao, and J.K. Reddy. 1997. Isolation and characterization of $\mathrm{PBP}$, a protein that interacts with peroxisome proliferator-activated receptor. I. Biol. Chem. 272: 25500-25506.

Zhu, Y., C. Qi, S. Jain, M.M. Le Beau, R. Espinosa, 3rd, G.B. Atkins, M.A. Lazar, A.V. Yeldandi, M.S. Rao, and J.K. Reddy. 1999. Amplification and overexpression of peroxisome proliferator-activated receptor binding protein (PBP/ PPARBP) gene in breast cancer. Proc. Natl. Acad. Sci. 96: $10848-10853$.

Zwijsen, R.M., E. Wientjens, R. Klompmaker, J. van der Sman, R. Bernards, and R.J. Michalides. 1997. CDK-independent activation of estrogen receptor by cyclin D1. Cell 88: 405415 . 


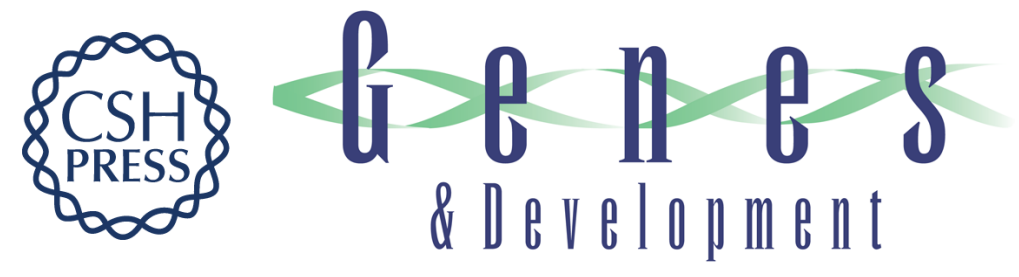

\section{The coregulator exchange in transcriptional functions of nuclear receptors}

Christopher K. Glass and Michael G. Rosenfeld

Genes Dev. 2000, 14:

Access the most recent version at doi:10.1101/gad.14.2.121

$\begin{array}{ll}\text { References } & \text { This article cites } 231 \text { articles, } 95 \text { of which can be accessed free at: } \\ \text { http://genesdev.cshlp.org/content/14/2/121.full.html\#ref-list-1 }\end{array}$

License

Email Alerting Receive free email alerts when new articles cite this article - sign up in the box at the top Service right corner of the article or click here.

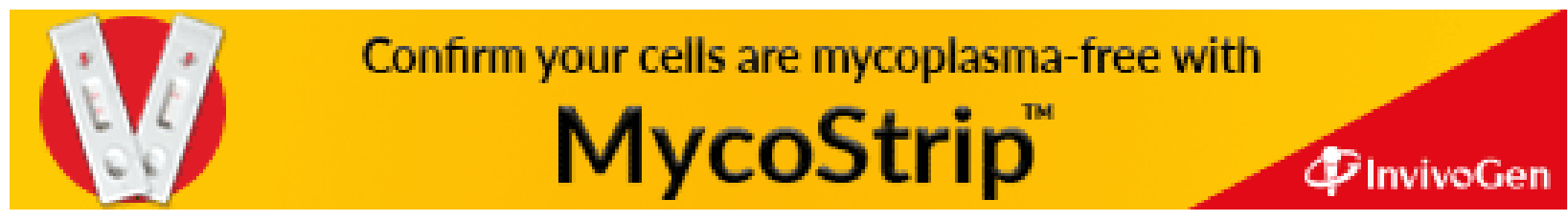

